NBER WORKING PAPER SERIES

RISK, UNCERTAINTY

AND EXCHANGE RATES

Robert J. Hodrick

Working Paper No. 2429

NATIONAL BUREAU OF ECONOMIC RESEARCH

1050 Massachusetts Avenue

Cambridge, MA 02138

November 1987

The research reported here is part of the NBER's research program in International Studies. Any opinions expressed are those of the author and not those of the National Bureau of Economic Research. 
NBER Working Paper \#2429

November 1987

Risk, Uncertainty and Exchange Rates

\begin{abstract}
This paper explores a new direction for empirical models of exchange rate determination. The motivation arises from two well documented facts, the failure of log-linear empirical exchange rate models of the 1970's and the variability of risk premiuns in the forward market. Rational maximizing models of economic behavior imply that changes in the conditional variances of exogenous processes, such as future monetary policies, future government spending, and future rates of income growth, can have a significant effect on risk premiums in the foreign exchange market and can induce conditional volatility of spot exchange rates. I examine theoretically how changes in these exogenous conditional variances affect the level of the current exchange rate, and I attempt to quantify the extent that this channel explains exchange rate volatility using autoregressive conditional heteroscedastic models.
\end{abstract}

Robert J. Hodrick

Kellogg Graduate School of Management Northwestern University Evanston, IL 60208

(312) 491-8339 
I. Introduction

Most of the existing empirical models of exchange rates were designed to address questions about the influence of the first moments of exogenous processes on exchange rates. The models are usually linear in natural logarithms, and their solutions express logarithms of exchange rates as the discounted expected values of the logarithms of the future driving processes with constant rates of discount. Many of the models assume that risk neutrality provides a good approximation of the preferences of actual economic agents.

Since only the first moments of exogenous processes matter for economic behavior in these models, they are poorly equipped to answer questions such as how does the exchange rate respond to an increase in the uncertainty associated with the amount of government spending in the economy. They also cannot address questions regarding how changes in the uncertainty of the monetary policies of countries or changes in the uncertainty associated with the rates of technological change of the countries affect exchange rates. Explicit nonlinear models based on the maximizing behavior of risk-averse agents are able to address these questions because they model how risk-averse individuals respond to perceived changes in the uncertainty of their environment. The goal of this paper is to address some of these questions explicitly with both theory and some initial empirical work.

There are several additional motivations for the first sections of this paper. The first comes from the work of Meese and Rogoff (1983a, 1983b, 1986), who explore the out-of-sample predictive ability of the log-linear models of the 1970's. These models were the first rational expectations models that studied exchange rate determination in a framework of asset 
market equilibrium. $^{1}$ A striking finding of their research is the general failure of these models to beat the prediction that the exchange rate follows a random walk, even when the models are given ex post values of the righthand-side variables. ${ }^{2}$ One aspect of the economy that is ignored in constructing linear models is the nature of risk that agents must bear. Meese and Rogoff (1983b) suggest that time-varying risk premiums could be an important determinant of their findings although they express skepticism about the likelihood of this being the complete explanation. Part of this reasoning is attributable to the fact that Meese and Rogoff include nominal interest rate differentials in their specifications which will capture some of the influence of risk.

A second motivation is the findings of Fama (1984) and Hodrick and Srivastava (1986). Fama (1984) investigated regressions of the ex post rate of change of an exchange rate (the rate of depreciation of one currency relative to another) on the forward premium, which can be defined to be the expected rate of depreciation plus a risk premium. He demonstrated that the results can be interpreted as providing evidence that risk premiums in the forward exchange market are more variable than expected rates of depreciation. This interpretation is valid under the hypothesis of rational expectations and under the assumptions that the sample statistics are converging to the true moments of the population and that the asymptotic standard errors are correct. Although the findings were somewhat troublesome to Fama (1984), there is abundant current evidence across many asset markets that expected returns and risk premiums do vary through time. ${ }^{3}$

Time variation in risk premiums complicates discussions of the appropriateness of the levels of stock and bond prices, since they are no 
longer the present discounted values of streams of payments discounted at a constant rate. It also suggests that the variables that cause time-varying risk premiums in the forward foreign exchange market and other asset markets are potentially important in the determination of spot exchange rates and the levels of other asset prices. ${ }^{4}$

A third motivation is the recent interesting partial equilibrium exercise that Frankel and Meese (1987) conducted to examine how much a change in the conditional variance of the future spot exchange rate affects the level of the current exchange rate in the context of a simple portfolio balance model. Their surprising back-of-the-envelope calculations indicate that plausible changes in the conditional variance of the exchange rate can have substantial effects on the level of the spot rate. Frankel and Meese (1987) acknowledge that their exercise is partial equilibrium (since they hold the expected future exchange rate constant), and they suggest that the two-period mean-variance model is unlikely to be appropriate in an environment in which conditional variances are moving. The problem is that the model ignores the demands of investors to hedge against changes in the investment opportunity set. Intertemporal general equilibrium models are required to investigate this type of phenomenon.

Finally, the fourth motivation comes from the recent theoretical exercises that Abel (1986) and Giovannini (1987) have performed. They examine how a change in the conditional variance of an exogenous aggregate real dividend process affects the level of stock prices in general equilibrium. ${ }^{5}$ Both authors demonstrate that the effect depends on the degree of relative risk aversion or the rate of intertemporal substitution of a representative agent, but their models predict opposite directions of the 
effect. Abel (1986) works in a simple version of the Lucas (1978) model, which is a real barter model. Giovannini (1987) works in a simple version of Svensson's (1985b) model, which modified the timing of transactions in the monetary model of Lucas (1982).

The analysis is conducted in the next four sections. Section II specifies the preferences and budget constraints of the countries, and defines an equilibrium. In section.III, I provide closed form solutions for some of the key variables of the model under assumptions on the time series properties of the exogenous processes. Section IV contains the empirical analysis associated with the model. Some concluding remarks are contained in section $\mathrm{V}$.

\section{A Modified Svensson Mode1}

In this section I explore a version of the cash-in-advance model presented in Svensson (1985a, 1985b) and discussed in Stockman and Svensson (1987). The model is a modification of the monetary model first presented in Lucas (1982). I add a discussion of exogenous fiscal policy, and I examine time-varying conditional variances of the exogenous processes as in Abel (1986) and Giovannini (1987). These extensions allow consideration of the issues outlined in the introduction regarding the influence of uncertainty on the risk premium in the foreign exchange market and on the level of the exchange rate and its volatility.

\section{II.A. Countries and Endowments}

There are two countries, denoted country one and country two. There are two goods in the world that are the endowments of the two countries. The 
endowments are exogenous and nonstorable, and the realizations of the endowments are denoted $Y_{1 t}$ and $Y_{2 t}$, for the goods of country one and two, respectively. ${ }^{6}$ The timing of the model follows Svensson (1985a) in assuming that goods markets are open in the beginning of each period and asset markets are open at the end of each period.

The endowments are elements of the exogenous state of the world at time $t$ that is denoted $x_{t}$. The precise complete definition of the state of the world will be given below. It will also be demonstrated that the state follows a first-order Markov process with transition density given by $F\left(x_{t+1} \mid x_{t}\right)$.

\section{II.B. Government Sectors}

The government of each country buys some of that country's goods in the competitive market for each good. The exogenous amount purchased each period is denoted $G_{i t}$, for $i=1,2$. The precise time series processes for real endowments and real government spendings are specified below.

Each government is subject to a budget constraint that requires balance between purchases of goods and taxes collected net of securities issued and redeemed. For simplicity, I consider only real head taxes, which are denoted $\tau_{i t}$, for $i=1,2 .^{7}$ Taxes are paid to the government at the asset market each period. The governments can also issue state contingent claims to nominal money where $B_{i t}\left(x_{t}\right)$ is the amount of currency $i$ that the government of country $i$ promises at time $t-1$ to pay at time $t$ contingent on the state of the world being $x_{t}$. The assumption that governments only issue state contingent claims on their own money stocks is not substantive. The money stocks are also exogenous and are given by $M_{i t}, i=1,2$, for the outstanding 
quantities of monies at the end of period $t-1$. The money of country one will be called the "dollar," and the money of country two will be called the "pound."

The governments' flow budget constraints are therefore

$$
\begin{aligned}
G_{i t}= & \tau_{i t}+\left[\int n_{i}\left(x_{t+1}, x_{t}\right) B_{i t+1}\left(x_{t+1}\right) d x_{t+1}-B_{i t}\left(x_{t}\right)\right] / P_{i t} \\
& +\left(M_{i t+1}-M_{i t}\right) / P_{i t}, \quad i=1,2 .
\end{aligned}
$$

In (1) the function $n_{i}\left(x_{t+1}, x_{t}\right)$ is the endogenous nominal pricing kernel associated with money $i$. It provides values in terms of money $i$ at time $t$ in state $x_{t}$ of promises to state-contingent amounts of money $i$ at time $t+1$ given state $x_{t+1}$. The dollar price of good one is $P_{1 t}$, and the pound price of good two is $P_{2 t}$.

The governments are also subject to cash-in-advance constraints in their purchases in the goods markets, although since they have access to the printing press, they are not limited in their nominal spending by their previous accumulation of money. If $\mathrm{M}_{i t}^{\mathrm{g}}$ is defined to be the amount of money that the government of country $i$ acquired in the asset market at time $t-1$, then the cash-in-advance constraints are

$$
P_{i t} G_{i t} \leq M_{i t}^{G}+\left(M_{i t+1}-M_{i t}\right), \quad i=1,2 .
$$

The time series of government spending, taxation, and money creation are assumed to be exogenous, and the government is assumed to issue debt in a fashion consistent with its budget constraint. The exogenous gross rate of monetary growth of country $i$ in period $t$ is $\Omega_{i t} \equiv M_{i t+1} / M_{i t}, i=1,2$. 


\section{II.C. Preferences and Budget Constraints}

The preferences of agents in each country are assumed to be homothetic, which allows aggregation into a representative consumer, and the preferences of the two representative agents are assumed to be identical. It is also assumed that the representative agents have identical initial wealth levels and that they are taxed equally by the two countries as in Sargent (1987). These assumptions facilitate the discussion of an equilibrium, since they lead to the perfectly pooled equilibrium of Lucas (1982).

The objective function of the representative consumer of either country is to maximize expected lifetime utility as in

$$
\mathrm{E}_{0}\left\{\sum_{t=0}^{\infty} \beta^{\mathrm{t}} \mathrm{U}\left(\mathrm{C}_{1 t}, \mathrm{C}_{2 t}\right)\right\}, \quad 0<\beta<1
$$

by choice of consumption of the good of country one, $C_{1 t}$, and consumption of the good of country two, $\mathrm{C}_{2 t}{ }^{8}$ In $(3), \mathrm{E}_{0}(\cdot)$ is the expectation operator conditional on initial information in period zero. It is assumed that the period utility function, $U(\cdot, \cdot)$, is sufficiently concave that the Inada conditions are satisfied and an internal equilibrium is guaranteed. 9

Information relevant to the decisions for the period, that is the value of the elements of $x_{t}$, is assumed to be obtained at the beginning of the period. At that time the representative consumer faces two cash-in-advance constraints that dictate the quantities of each good that can be consumed. In the period $t-1$ asset market the representative agent of each country acquires $M_{i t}^{P}$ of currency $i$. In period $t$ the purchasing power of the dollar in term of good one is $\Pi_{1 t} \equiv\left(1 / P_{1 t}\right)$ and the purchasing power of the pound in terms of good one is $\Pi_{2 t}=\left(S_{t} / P_{1 t}\right)$, where $S_{t}$ is the exchange rate of dollars per pound. The cash-in-advance constraints are presented in real terms as 
(4a) $\quad C_{1 t} \leq M_{1 t}^{P} \Pi_{1 t}$,

(4b) $\quad \theta_{t} \mathrm{C}_{2 t} \leq \mathrm{M}_{2 t}^{\mathrm{P}} \Pi_{2 t}$,

and the relative price of good two in terms of good one, which can be thought of as the real terms of trade of country one, is $\theta_{t}=S_{t} P_{2 t} / P_{1 t}$. Although this expression defines a terms of trade, it should be remembered that it is not possible to trade goods for goods within a period. It is also not possible to trade money for money at the beginning of the period, which means that the exchange rate is truly an asset price. Stockman and Svensson (1987) argue that the spot rate defined here as $S_{t}$ is really a forward rate since delivery is not immediate. While this is true, it is also the case that the spot rate discussed in the typical empirical study of exchange rates is for delivery in one or two business days, depending on the currencies.

The budget constraint of the consumer during a period requires that his purchases of assets in the asset market be less than or equal to his wealth at that time. Agents are assumed to be able to trade titles to the endowment processes of the two countries. The number of titles or shares to the two endowments purchased by the agent at the time $t$ asset market is denoted $Z_{i t+1}$ with dollar prices of the shares denoted $Q_{i t}$, for $i=1,2$. The total number of shares is normalized to unity for each of the two shares to endowments. The consumers also can purchase state-contingent monies, where $B_{i t}^{P}\left(x_{t}\right)$ is the amount of money $i$ that the consumer purchased at the time $t-1$ asset market for delivery at the time $t$ asset market conditional on the state being $x_{t}$. The resources available to the agent in the asset market are any unspent monies from the two consumption goods markets, the payoffs on the shares to the endowments that they own plus the ability to resell the shares, and the 
state-contingent payoffs of monies that they own, but minus the tax liabilities. The budget constraint in period $t$ is

$$
\begin{aligned}
& \Pi_{1 t} M_{1 t+1}^{p}+\Pi_{2 t} M_{2 t+1}^{p}+\Pi_{1 t} \int n_{1}\left(x_{t+1}, x_{t}\right) B_{1 t+1}^{p}\left(x_{t+1}\right) d x_{t+1} \\
& +\Pi_{2 t} \int n_{2}\left(x_{t+1}, x_{t}\right) B_{2 t+1}^{p}\left(x_{t+1}\right) d x_{t+1}+\Psi_{1 t} z_{1 t+1}+\Psi_{2 t} z_{2 t+1} \leq \\
& \left(\Pi_{1 t} M_{1 t}^{P}-C_{1 t}\right)+\left(\Pi_{2 t} M_{2 t}^{P}-\theta_{t} C_{2 t}\right)+\Pi_{1 t} B_{1 t}^{P}\left(x_{t}\right)+\Pi_{2 t} B_{2 t}^{P}\left(x_{t}\right) \\
& +\left(\Psi_{1 t}+Y_{1 t}\right) Z_{1 t}+\left(\Psi_{2 t}+\theta_{t} Y_{2 t}\right) Z_{2 t}-(1 / 2)\left(\tau_{1 t}+\theta_{t} \tau_{2 t}\right) .
\end{aligned}
$$

In (5) the real price in terms of good one of a share of the endowment in country i is $\Psi_{i t} \equiv Q_{i t} / P_{1 t}, i=1,2$.

By adding the real value of current consumption and the real tax liabilities to both sides of (5), the right-hand side of the modified (5) is defined to be real wealth, which is denoted

$$
\begin{aligned}
W_{t} \equiv \Pi_{1 t^{M}}{ }_{1 t}^{P}+\Pi_{2 t} M_{2 t}^{P}+\Pi_{1 t} B_{1 t}^{P}\left(x_{t}\right)+\Pi_{2 t} B_{2 t}^{p}\left(x_{t}\right) \\
+\left(\Psi_{1 t}+Y_{1 t}\right) Z_{1 t}+\left(\Psi_{2 t}+\theta_{t} Y_{2 t}\right) Z_{2 t} .
\end{aligned}
$$

\section{II.D. Solution of the Agent's Problem}

In order to study an equilibrium of this economy, consider the value function of the agent's problem. The consumer has current real wealth and real stocks of money, and he is facing uncertainty about the future that can be characterized by the probability distribution of future states of the world. Hence, the value function of the agent's problem is

$$
\begin{aligned}
& V\left(W_{t}, \Pi_{1 t} M_{1 t}^{p}, \Pi_{2 t} M_{2 t}^{p}, x_{t}\right)=\max \left\{U\left(C_{1 t}, C_{2 t}\right)+\right. \\
& \left.\beta \int V\left(W_{t+1}, \Pi_{1 t+1} M_{1 t+1}^{p}, \Pi_{2 t+1} M_{2 t+1}^{P}, x_{t+1}\right) F\left(x_{t+1} \mid x_{t}\right) d x_{t+1}\right\},
\end{aligned}
$$


where the maximization is over current choices of consumption goods and new holdings of monies and other assets and is subject to the constraints in (4) and (5). The assumption of rational expectations is employed in (7) because the conditional expectation of the agent is taken with respect to the true transition probability of the future state.

If $\lambda_{t}$ is the multiplier for the period-t budget constraint given by (5), $\nu_{1 t}$ is the multiplier for the period-t dollar-good cash-in-advance constraint given by (4a), and $\nu_{2 t}$ is the multiplier for the period-t pound-good cash-inadvance constraint given by ( $4 \mathrm{~b})$, the first order conditions for the agent's problem may be written as

$$
\begin{aligned}
& U_{1 t}=\lambda_{t}+\nu_{1 t}, \\
& u_{2 t}=\left(\lambda_{t}+\nu_{2 t}\right) \theta_{t}, \\
& \lambda_{t} \Pi_{1 t}=\beta E_{t}\left[\left(\lambda_{t+1}+\nu_{1 t+1}\right) \Pi_{1 t+1}\right], \\
& \lambda_{t} \Pi_{2 t}=\beta E_{t}\left[\left(\lambda_{t+1}+\nu_{2 t+1}\right) \Pi_{2 t+1}\right], \\
& \lambda_{t} \Psi_{1 t}=\beta E_{t}\left[\left(\Psi_{1 t+1}+Y_{1 t+1}\right) \lambda_{t+1}\right], \\
& \lambda_{t} \Psi_{2 t}=\beta E_{t}\left[\left(\Psi_{2 t+1}+\theta_{t+1} Y_{2 t+1}\right) \lambda_{t+1}\right], \\
& \lambda_{t} \Pi_{1 t} n_{1}\left(x_{t+1}, x_{t}\right)=\beta \lambda_{t+1} \Pi_{1 t+1} F\left(x_{t+1} \mid x_{t}\right), \\
& \lambda_{t} \Pi_{2 t} n_{2}\left(x_{t+1}, \quad \forall x_{t+1},\right.
\end{aligned}
$$

In $(8 a, b)$ the partial derivative of the period utility function with respect to its $i$ th argument is denoted $U_{i t}$. In addition to ( $\left.8 a-h\right)$, each cash-inadvance constraint in (4) holds with equality when its associated multiplier is strictly greater than zero, and if the multiplier equals zero, the constraint is not binding. All of the expectations in ( $8 c-f$ ) are conditional expectations with respect to the density function of $x_{t+1}$ given $x_{t}$. 
The interpretation of $(8 a-h)$ is straightforward. Equation (8a) relates the marginal utility of consumption of good one to the marginal value of real wealth in units of good one plus the marginal value of the real dollar money balances of the agent. Similarly, (8b) relates the marginal utility of good two to the marginal value of wealth plus the marginal value of the real pound money balances held by the agent where both multipliers are multiplied by the relative price of good two in terms of good one because they are in units of good one. An important aspect of these two expressions is that the current marginal utility of consumption is not equated to the marginal value of wealth unless the cash-in-advance constraint associated with that good is not binding. 10

Equations $(8 c-h)$ are the Euler equations for the investment decisions of the agent. Equations $(8 c-d)$ are the Euler equations associated with the decisions to increase money balances in period $t$. The decision to hold an additional unit of nominal money involves a tradeoff of the product of the current real value of the money in terms of good one and the current marginal value of wealth against the expected utility value of the money in the next period's goods market which is its real purchasing power in terms of good one times the marginal value of wealth plus the marginal value of money at that time.

Equations $(8 e-f)$ are the Euler equations associated with the purchases of shares in the endowments. Investment at time $t$ in a title to future output requires a utility sacrifice given by the product of the current real price of the asset and the current marginal value of wealth. Since all assets, other than monies, pay off and can be resold only in the next period's asset market, which is after consumption in that period, the utility 
gain to purchasing an asset is the expectation of the product of the real resources available from holding the asset with the marginal value of wealth at time $t+1$.

Equations $(8 \mathrm{~g}-\mathrm{h})$ involve the purchase of state-contingent monies for delivery in the next asset market. If a unit of money $i$ for delivery in a particular state $x_{t+1}$ is purchased today at a nominal price of $n_{i}\left(x_{t+1}, x_{t}\right)$, the agent sacrifices real value given by the current purchasing power of that money times the marginal value of wealth. The value received in return is the real value of the unit of money conditional on the realization of the particular state times the marginal value of wealth in that state times the probability of that state being realized. These equations must hold for all possible future states.

\section{II.E. Definition of an Equilibrium}

Given the setup of the model at this point, it is useful to set out the definition of an equilibrium.

An equilibrium is defined to be a set of initial conditions $\left\{M_{i 0}>0, B_{i 0}\left(x_{0}\right), i=1,2\right\}$ and stochastic processes for the exogenous variables $\left\{Y_{i t}, G_{i t},{ }_{i t}, M_{i t+1}^{g}, M_{i t+1}, i=1,2\right\}_{t=0}^{\infty}$, the endogenous choice variables $\left\{C_{i t}, M_{i t+1}^{P}, B_{i t+1}^{P}\left(x_{t+1}\right), z_{i t+1}, i=1,2\right\}_{t=0}^{\infty}$, the prices of goods and assets $\left\{\Pi_{i t}, \theta_{t}, \Psi_{i t}, i=1,2\right\}_{t=0}^{\infty}$, which are functions of the current state of the economy, and the pricing functions $n_{i}\left(x_{t+1}, x_{t}\right), i=1,2$, such that the following conditions are satisfied:

(i) The two government budget constraints in (1) are balanced for all $t \geq 0$, and the cash-in-advance constraints (2) are satisfied with 
equality.

(ii) Given the pricing functions for contingent money purchases, the real share prices, and the stochastic processes for ' $\tau_{i t}$ ' $\Pi_{i t}$ ' $Y_{i t}$ ' $i=1,2$ ) and the initial conditions, the choices of the households for consumption goods, money holdings, contingent claim purchases, and share purchases solve the agent's constrained maximization problem.

(iii) There is market clearing in the competitive markets for goods, shares and contingent claims on monies for all periods $t \geq 0$, where market clearing is given by the following:

(9a)

$$
2 C_{i t}+G_{i t}=Y_{i t}, \quad i=1,2
$$

$$
z_{i t+1}=(1 / 2), \quad i=1,2 \text {, }
$$

$$
M_{i t+1}=M_{i t+1}^{g}+2 M_{i t+1}^{P}, \quad i=1,2,
$$

$$
B_{i t+1}\left(x_{t+1}\right)=2 B_{i t+1}^{P}\left(x_{t+1}\right), \quad i=1,2, \forall x_{t+1} .
$$

One equilibrium that can be studied in this model is the perfectly pooled equilibrium of Lucas (1982), in which agents equally share the endowments, net of government consumption, of the two countries.

\section{Closed-Form Equilibrium Solutions}

In developing explicit solutions to the model I have chosen to work with particular time series properties for the exogenous variables. The processes on endowments and gross rates of growth of money supplies are assumed to be conditionally log normal. If lower case letters indicate natural logarithms of upper case counterparts, then the processes for real endowments and gross 
rates of growth of money supplies are assumed to be

$$
\begin{array}{ll}
\text { (10a) } \mathrm{y}_{1 \mathrm{t}+1}=\rho_{1} \mathrm{y}_{1 \mathrm{t}}+\left(1-\rho_{1}\right) \mathrm{y}_{1}+\varepsilon_{1 t+1}, & 0 \leq\left|\rho_{1}\right| \leq 1, \\
\text { (10b) } \mathrm{y}_{2 t+1}=\rho_{2} \mathrm{y}_{2 t}+\left(1-\rho_{2}\right) \mathrm{y}_{2}+\varepsilon_{2 t+1}, & 0 \leq\left|\rho_{2}\right| \leq 1, \\
\text { (10c) } \omega_{1 \mathrm{t}+1}=\rho_{3} \omega_{1 t}+\left(1-\rho_{3}\right) \omega_{1}+\varepsilon_{3 t+1}, & 0 \leq\left|\rho_{3}\right| \leq 1, \\
\text { (10d) } \omega_{2 t+1}=\rho_{4} \omega_{2 t}+\left(1-\rho_{4}\right) \omega_{2}+\varepsilon_{4 t+1}, & 0 \leq\left|\rho_{4}\right| \leq 1 .
\end{array}
$$

In $(10 \mathrm{a}, \mathrm{b})$ the $\mathrm{y}_{i}, \mathrm{i}=1,2$, are the unconditional values of the logarithms of the endowments of the two countries, and in $(10 c, d)$ the $\omega_{i}, i=1,2$, are the logarithms of the two unconditional gross rates of nominal monetary growth. Each $\varepsilon_{i t+1}, i=1,4$, is assumed to be normally distributed with conditional mean equal to zero and conditional variance given by $h_{i t}, i=1$, 4. The series are assumed to be conditionally uncorrelated for simplicity.

I have also chosen to make simplifying assumptions about the distributions of the shares of government spending. In order to simplify later presentations, let the fraction of good $i$ that the government buys be $\xi_{i t} \equiv\left(G_{i t} / Y_{i t}\right)$. I assume that the $\xi_{i t}$ can be described by the following processes:

$$
\begin{array}{ll}
\xi_{1 t+1}=\rho_{5} \xi_{1 t}+\left(1-\rho_{5}\right) \xi_{1}+\varepsilon_{5 t+1}, & 0 \leq\left|\rho_{5}\right|<1, \\
\xi_{2 t+1}=\rho_{6} \xi_{2 t}+\left(1-\rho_{6}\right) \xi_{2}+\varepsilon_{6 t+1}, & 0 \leq\left|\rho_{6}\right|<1,
\end{array}
$$

where $\varepsilon_{5 t+1}$ is distributed uniformly on the interval $\left[-h_{5 t}, h_{5 t}\right]$, and $\varepsilon_{6 t+1}$ is distributed uniformly on the interval $\left[-h_{6 t}, h_{6 t}\right]$.

I also assume that the parameters characterizing the conditional variances of the six exogenous processes follow simple autoregressions such that 


$$
E_{t}\left(h_{i t+1}\right)=\phi_{i} h_{i t}+\left(1-\phi_{i}\right) h_{i}, \quad i=1,6 \text {, }
$$

where $h_{i}$ is the unconditional variance of the process for $i=1,4$, and $(1 / 3)\left(h_{i}\right)^{3}$ is the unconditional variance for the government spending processes, $i=5,6$.

The state of the economy can now be defined to be the $x_{t}=\left(y_{i t}, m_{i t+1}\right.$, $\left.\omega_{i t}, \xi_{i t}, \tau_{i t}, i=1,2, h_{j t}, j=1,6\right)$, and with the assumption that the taxation policies are Markov processes, the $x_{t}$ vector is a Markov process as was assumed in the beginning of the model.

Since I am interested in obtaining closed-form solutions to the model, I choose the period utility function to be

$$
U\left(C_{1 t}, C_{2 t}\right)=[1 /(1-\gamma)] C_{1 t}^{1-\gamma}+[1 /(1-\delta)] C_{2 t}^{1-\delta}
$$

In (13) I have used the constant relative risk aversion utility function that Abel (1986) and Giovannini (1987) use. In dynamic applications under uncertainty these utility functions have the unfortunate attribute of specifying the agent's aversion to risk with the same parameter that characterizes the agent's preferences for intertemporal substitution.

In a certainty environment, the elasticity of intertemporal substitution that describes the percentage change in the ratio of consumption in period $t+1$ to consumption in period $t$ in response to a percentage change in the real return on saving is the reciprocal of the coefficient of relative risk aversion, $\boldsymbol{\gamma}$. An increase in the real return has both income and substitution effects on current consumption. The income effect tends to increase current consumption since any saving now has a higher return, and the substitution effect tends to decrease current consumption since future consumption is now less expensive. When $\gamma<1$, the substitution effect dominates the income 
effect, and current consumption falls with an increase in the real return. When $\gamma=1$, the utility function is logarithmic, and the income effect and the substitution effect cancel making current consumption constant. When $\gamma>$ 1 , the income effect outweighs the substitution effect and current consumption rises. These responses are useful in determining how asset prices must respond in general equilibrium in response to a shock to the economy, because we know that the current endowment must be consumed.

In this case the equilibrium marginal utilities of consumption are

(14a) $\quad U_{1 t}=\left[\left(Y_{1 t}-G_{1 t}\right) / 2\right]^{-\gamma}$, and

$$
\mathrm{U}_{2 t}=\left[\left(\mathrm{Y}_{2 t}-\mathrm{G}_{2 \mathrm{t}}\right) / 2\right]^{-\delta} \text {. }
$$

From the definition of the shares of government spending in the economy, it follows that $U_{1 t}=2^{\gamma}\left(1-\xi_{1 t}\right)^{-\gamma} Y_{1 t}^{-\gamma}$, and $U_{2 t}=2^{\delta}\left(1-\xi_{2 t}\right)^{-\delta} Y_{2 t}^{-\delta}$.

I also follow Giovannini (1987) and investigate explicitly only the case in which the parameters of the model result in an equilibrium in which the money multipliers are always positive. ${ }^{11}$ In this case the cash-in-advance constraints in (4) hold as equalities. One problem with this equilibrium is that it implies unitary velocities of circulation of the monies. This may be less of a problem than ordinarily thought since we do not observe the length of the period. The observable relation is between a time averaged flow of income and the point in time stocks of monies. Svensson (1985) and Flood (1987) also note that the thought experiment of changing the rate of growth of the money supply will typically change the length of the period over which the optimization is conducted. This will also result in a variable velocity when measurements are taken over constant time intervals although clearly such changes in the period are not considered here. 
With the assumption that the governments' cash-in-advance constraints hold as equalities, the goods-market clearing conditions and the money-market clearing conditions can be used to find expressions for the real purchasing powers of the two monies which are given by the following:

(15a) $\quad \Pi_{1 t}=Y_{1 t} / M_{1 t+1}$,

$$
\Pi_{2 t}=\theta_{t} Y_{2 t} / M_{2 t+1}
$$

In (15b) the dependence of $\Pi_{2 t}$ on the relative price $\theta_{t}$ indicates that this is not a final expression since the relative price is an endogenous variable.

The solution for the marginal utility of wealth is readily obtainable from (8a) and (8c), using the expressions in (14a) and (15a).

$$
\lambda_{t}\left(\mathrm{Y}_{1 \mathrm{t}} / \mathrm{M}_{1 t+1}\right)=\beta \mathrm{E}_{\mathrm{t}}\left[2^{\gamma}\left(1-\xi_{1 t+1}\right)^{-\gamma_{\mathrm{Y}_{1 t+1}}^{-\gamma}}\left(\mathrm{Y}_{1 t+1} / \mathrm{M}_{1 t+2}\right)\right] \text {, or }
$$

$$
\lambda_{t}=\beta 2^{\gamma} E_{t}\left[\left(1-\xi_{1 t+1}\right)^{-\gamma} Y_{1 t+1}^{1-\gamma} / Y_{1 t^{n_{1 t+1}}}\right]
$$

The complete solution requires substitution from the specification of the time series processes on the exogenous variables.

A similar set of substitutions from (8b), (8d), (14b) and (15b) allows for a solution to the terms of trade as

$$
\begin{aligned}
& \lambda_{t} \theta_{t}\left(Y_{2 t} / M_{2 t+1}\right)=\beta E_{t}\left[2^{\delta}\left(1-\xi_{2 t+1}\right)^{-\delta} Y_{2 t+1}^{-\delta}\left(Y_{2 t+1} / M_{2 t+2}\right)\right] \text {, or } \\
& \theta_{t}=\beta 2^{\delta} E_{t}\left[\left(1-\xi_{2 t+1}\right)^{-\delta} Y_{2 t+1}^{1-\delta} / Y_{2 t} \Omega_{2 t+1}\right] / \lambda_{t} .
\end{aligned}
$$

Equations $(15 a, b),(16)$ and (17) can now be combined to solve for the exchange rate, given the assumed exogenous processes of the model, since the exchange rate is simply $s_{t}=\Pi_{2 t} / \Pi_{1 t}=\theta_{t}\left(Y_{2 t} / M_{2 t+1}\right) /\left(Y_{1 t} / M_{1 t+1}\right)$. 
III.A. Solution for the Exchange Rate

The solution for the exchange rate is easily presented by taking the natural logarithm of exchange rate and substituting from the appropriate expressions using the absence of correlation between the exogenous processes:

$$
\begin{aligned}
s_{t}= & \alpha_{s 0}+\alpha_{s 1} m_{1 t+1}-\alpha_{s 2} m_{2 t+1}-\alpha_{s 3} \Xi_{1 t}+\alpha_{s 4} \Xi_{2 t}-\alpha_{s 5} y_{1 t}+\alpha_{s 6} y_{2 t} \\
& +\alpha_{s 7} \omega_{1 t}-\alpha_{s 8} \omega_{2 t}-\alpha_{s 9} h_{1 t}+\alpha_{s 10} h_{2 t}-\alpha_{s 11} h_{3 t}+\alpha_{s 12} h_{4 t}
\end{aligned}
$$

In (18) $\Xi_{1 t} \equiv \ln \left(E_{t}\left[\left(1-\xi_{1 t+1}\right)^{-\gamma}\right]\right)$, and $\Xi_{2 t} \equiv \ln \left\{E_{t}\left[\left(1-\xi_{2 t+1}\right)^{-\delta}\right]\right\}$, which are given by the following:

(19a) $\Xi_{1 t}=\ln \left\{\left[-\left(1-\mu_{1 t}-h_{5 t}\right)^{1-\gamma}+\left(1-\mu_{1 t}+h_{5 t}\right)^{1-\gamma}\right] /(1-\gamma) 2 h_{5 t}\right\}$,

(19b) $\Xi_{2 t}=\ln \left\{\left[-\left(1-\mu_{2 t}-\mathrm{h}_{6 t}\right)^{1-\delta}+\left(1-\mu_{2 t}+\mathrm{h}_{6 t}\right)^{1-\delta}\right] /(1-\delta) 2 \mathrm{~h}_{6 t}\right\}$.

In (19a) $\mu_{1 t} \equiv \rho_{5} \xi_{1 t}+\left(1-\rho_{5}\right) \xi_{1}$, and in (19b) $\mu_{2 t} \equiv \rho_{6} \xi_{2 t}+\left(1-\rho_{6}\right) \xi_{2}$.

In (18) all of the $\alpha_{s}$ parameters are defined to be positive when there is positive persistence of endowment processes and intertemporal substitution is high $(\gamma<1$ and $\delta<1)$. Their values are

$$
\begin{gathered}
\alpha_{s 1}=\alpha_{s 2}=\alpha_{s 3}=\alpha_{s 4}=1, \\
\alpha_{s 5}=(1-\gamma) \rho_{1}, \\
\alpha_{s 6}=(1-\delta) \rho_{2}, \\
\alpha_{s 7}=\rho_{3}, \\
\alpha_{s 8}=\rho_{4}, \\
\alpha_{s 9}=(1 / 2)(1-\gamma)^{2} \\
\alpha_{s 10}=(1 / 2)(1-\delta)^{2} \\
\text { and } \alpha_{s 11}=\alpha_{s 12}=(1 / 2)
\end{gathered}
$$

As in the monetary approach to the determination of the exchange rate, an increase in the money stock of country one or its rate of growth 
depreciates the dollar relative to the pound. The results for the level of a country's endowment is similar to the predictions of the monetary approach only when the intertemporal elasticity of substitution is high. Then, higher (lower) levels of output in country one (two) lead to an appreciation of the dollar relative to the pound. The results are reversed if intertemporal substitution is low $(\gamma>1$ and $\delta>1)$.

Additional insights in this approach center on the influence of the government spending variables and the conditional variances. Notice from (18) and (19a) that an increase in the expected share of country-one output that the government will take in the next period appreciates the dollar relative to the pound. Similarly, if less of country two's output is expected to be available next period, the pound appreciates relative to the dollar. These effects arise because of the influence of future government spending on the expected marginal utility of the respective goods. If less of country one's endowment is expected to be available for consumption next period, the relative price of the country-two good in terms of the countryone good, $\theta_{t}$, must rise. Since the purchasing powers of the dollar in terms of the country-one good and the pound in terms of the country-two good are determined strictly by the outstanding quantities of monies and the currently available endowments, the entire change in the relative price of the two goods is accomplished through the exchange rate.

An increase in the conditional variance of the country-one money growth rate or the country-one endowment process causes an appreciation of the dollar relative to the pound. Both effects arise because increases in either conditional variance increase the expected purchasing power of the dollar. Similarly, an increase in either the conditional variance of the pound 
monetary growth rate or the endowment of country two appreciates the pound relative to the dollar.

An increase in the conditional variance of the share of government spending in good one (two) causes an increase in $\Xi_{1 t}\left(\Xi_{2 t}\right)$ which also appreciates (depreciates) the dollar relative to the pound. These effects arise because an increase in the variance of the share of government spending increases the expected marginal utility of that good since agents are risk averse. These effects are derived formally in the Appendix.

\section{III.B. Solutions for Nominal Interest Rates}

Let $i_{1 t}$ be the risk-free nominal interest rate of country one on a continuously compounded basis. Hence, $\exp \left(-i_{1 t}\right)$ is the amount of dollars that one must sacrifice at the time $t$ asset market for a dollar delivered unconditionally at the time $t+1$ asset market. Let $i_{2 t}$ be the similarly defined pound nominal interest rate. From the definitions of the nominal interest rates, the nominal pricing kernels and $(8 \mathrm{~g}, \mathrm{~h})$ we know that

$$
\begin{aligned}
& \exp \left(-i_{1 t}\right)=\int n_{1}\left(x_{t+1}, x_{t}\right) d x_{t+1}=\beta E_{t}\left[\Pi_{1 t+1}{ }_{t+1} / \Pi_{1 t} \lambda_{t}\right], \text { and } \\
& \exp \left(-i_{2 t}\right)=\int n_{2}\left(x_{t+1}, x_{t}\right) d x_{t+1}=\beta E_{t}\left[\Pi_{2 t+1} \lambda_{t+1} / \Pi_{2 t} \lambda_{t}\right] .
\end{aligned}
$$

By taking natural logarithms of both sides of $(20 a, b)$ and exploiting the assumed time series processes of the exogenous variables, we have the following closed form solutions:

$$
\text { (21a) } \begin{gathered}
i_{1 t}=\alpha_{i 10}+\alpha_{i 11} \Xi_{1 t}-\alpha_{i 12} \ln \left(E_{t}\left[\left(1-\xi_{1 t+2}\right)^{-\gamma}\right]\right)+\alpha_{i 13}\left(y_{1 t}-y_{1}\right) \\
+\alpha_{i 14}\left(\omega_{1 t}-\omega_{1}\right)+\alpha_{i 15} h_{1 t}+\alpha_{i 16} h_{3 t} \text {, and }
\end{gathered}
$$


(21b) $i_{2 t}=\alpha_{i 20}+\alpha_{i 21} \Xi_{2 t}-\alpha_{i 22} \ln \left(E_{t}\left[\left(1-\xi_{2 t+2}\right)^{-\delta}\right]\right\}+\alpha_{i 23}\left(y_{2 t}-y_{2}\right)$

$$
+\alpha_{i 24}\left(\omega_{2 t}-\omega_{2}\right)+\alpha_{i 25} h_{2 t}+\alpha_{i 26} h_{4 t} .
$$

In $(21 a, b)$ under the assumptions of the model, all of the $\alpha$ coefficients cannot be signed because they depend on the degrees of intertemporal substitution, which are given by $\gamma^{-1}$ and $\delta^{-1}$. When intertemporal substitution for good one is high and with positive persistence of real endowments, all of the $\alpha_{i l}$ coefficients are positive, and their values are

$$
\begin{gathered}
\alpha_{i 10}=-\ln \beta+\omega_{1}-(1 / 2)\left(1-\phi_{1}\right)(1-\gamma)^{2} h_{1}-(1 / 2)\left(1-\phi_{3}\right) h_{3}, \\
\alpha_{i 11}=\alpha_{i 12}=1, \\
\alpha_{i 13}=\rho_{1}(1-\gamma)\left(1-\rho_{1}\right), \\
\alpha_{i 14}=\rho_{3}^{2}, \\
\alpha_{i 15}=(1 / 2)\left(1-\phi_{1}-\rho_{1}^{2}\right)(1-\gamma)^{2}, \text { and } \\
\alpha_{i 16}=(1 / 2)\left[\left(1-\phi_{3}\right)-\left(1+\rho_{3}\right)^{2}\right] .
\end{gathered}
$$

Higher than average rates of monetary growth increase nominal interest rates because they increase the expected rate of inflation.

If intertemporal substitution is strong $(\gamma<1)$ and with positive persistence of real endowments, higher than average endowments cause high nominal interest rates. The effect of the higher than usual endowment is to increase the purchasing power of money and to create expected inflation as the future purchasing power of money is expected to fall. This effect outweighs the real interest rate effect which would be to decrease nominal interest rates. Alternatively, if intertemporal substitution is low $(\gamma>1)$, a higher than average current endowment causes a fall in the nominal interest rate.

When intertemporal substitution for good two is high $(\delta<1)$ and with 
positive persistence in the good two endowment process, all of the $\alpha_{i 2}$ coefficients are positive, and their values are

$$
\begin{gathered}
\alpha_{i 20}=-\ln \beta+\omega_{2}-(1 / 2)\left(1-\phi_{2}\right)(1-\delta)^{2} h_{2}-(1 / 2)\left(1-\phi_{4}\right) h_{4}, \\
\alpha_{i 21}=\alpha_{i 22}=1, \\
\alpha_{i 23}=\rho_{2}(1-\delta)\left(1-\rho_{2}\right), \\
\alpha_{i 24}=\rho_{4}^{2} \\
\alpha_{i 25}=(1 / 2)\left(1-\phi_{2}-\rho_{2}^{2}\right)(1-\delta)^{2}, \text { and } \\
\alpha_{i 26}=(1 / 2)\left[\left(1-\phi_{4}\right)-\left(1+\rho_{4}\right)^{2}\right] .
\end{gathered}
$$

\section{III.C. Risk Premiums in the Forward Foreign Exchange Market}

Although no explicit forward foreign exchange market was introduced in the assets that agents trade in the asset market, arbitrage allows the pricing of forward contracts for delivery of money in the asset market next period. In order to prevent an arbitrage opportunity, it is known that the return from investing a dollar in a risk-free nominal dollar return has to be identical to the return from converting the dollar into pounds, investing the pounds in a risk-free nominal pound return, and making a forward contract to sell the pounds obtained in the investment in the forward market. This statement of interest rate parity requires that

$$
\exp \left(i_{1 t}\right)=\left(1 / S_{t}\right) \exp \left(i_{2 t}\right) F_{t}
$$

where $F_{t}$ is the contract price of dollars per pound in the time $t$ forward market for delivery and payment at time $t+1$.

The logarithmic expression of the risk premium in the forward market

that has been studied extensively in empirical analyses is $E_{t}\left(s_{t+1}\right)-f_{t}$, which from (22) is equivalent to $E_{t}\left(s_{t+1}-s_{t}\right)-\left(i_{1 t}-i_{2 t}\right)$. By taking the time $t$ expectation of (18) 
updated one period and subtracting (18) and the difference of (21a) and (21b) we have

$$
\begin{gathered}
E_{t}\left(s_{t+1}-f_{t}\right)=\alpha_{r 1} h_{1 t}-\alpha_{r 2} h_{2 t}+\alpha_{r 3} h_{3 t}-\alpha_{r 4} h_{4 t} \\
-\left\{E_{t}\left(\Xi_{1 t+1}\right)-\ln \left[E_{t}\left(1-\xi_{1 t+2}\right)^{-\gamma}\right]\right\}+\left\{E_{t}\left(\Xi_{2 t+1}\right)-\ln \left[E_{t}\left(1-\xi_{2 t+2}\right)^{-\delta}\right]\right\}
\end{gathered}
$$

where the $\alpha_{r}$ parameters are defined to be positive when intertemporal substitution is high for both goods and the values of the parameters are given by

$$
\begin{aligned}
& \alpha_{r 1}=(1 / 2) \rho_{1}^{2}(1-\gamma), \\
& \alpha_{r 2}=(1 / 2) \rho_{2}^{2}(1-\delta), \\
& \alpha_{r 3}=(1 / 2)\left(1+\rho_{3}\right)^{2}, \text { and } \\
& \alpha_{r 4}=(1 / 2)\left(1+\rho_{4}\right)^{2} .
\end{aligned}
$$

If risk premiums are highly variable as indicated in the analysis of Fama (1984) and Hodrick and Srivastava (1986) and if the model is true, the variability is produced by time variation in the conditional variances of the exogenous monetary growth rates and of the endowment processes. The variance of the share of the endowment that the government will take also affects the risk premium since $E_{t}\left(\Xi_{1 t+1}\right)$, the time $t$ expectation of the the logarithm of the expected value at time $t+1$ of $\left(1-\xi_{1 t+2}\right)^{-\gamma}$, is not in general equal to the logarithm of the expected value at time $t$ of $\left(1-\xi_{1 t+2}\right)^{-\gamma}$.

This section has established that as the conditional variances of the exogenous processes move through time they will cause movements in both the risk premium in the foreign exchange market and in the level of the spot exchange rate. The next section investigates whether these effects are present in the data. 


\section{An Empirical Investigation}

The model developed above has a number of strong testable implications. In the remainder of the paper I test a limited number of these new ideas. The most interesting new aspect of the model is that it indicates how the conditional variances of exogenous processes can be thought of as exogenous processes that influence the economy. Changes in the uncertainty in the economy interact with the risk aversion of economic agents to cause movements in asset prices such as interest rates and exchange rates. Since the conditional variance of a process is not directly observable, empirical work in this area must take a stand on measurements of conditional variances.

In this section I examine a recent econometric method that has been proposed for models of the conditional variances of economic processes. The only way that I have modelled these effects is with univariate autoregressive conditional heteroscedasticity (ARCH) or its generalized counterpart (GARCH). 12

A time series is said to have ARCH increments if the conditional variance of the innovation in the process relative to its past history depends on squared values of previous innovations. A GARCH process generalizes this dependence on past innovations to allow dependence on past values of the conditional variance. A typical time series $x_{t}$ is modelled here as an ARIMA process. The innovation in $x_{t}$ conditional on its past history is $\varepsilon_{t}$ which has the property that $E\left(\varepsilon_{t} \mid x_{t-1}, x_{t-2}, \ldots\right)=0$. In a GARCH model the conditional variance of $\varepsilon_{t}, v_{t-1}\left(\varepsilon_{t}\right) \equiv h_{t}$, and it is modelled as 


$$
h_{t}=\omega+\sum_{i=1}^{q} \alpha_{i} \varepsilon_{t-i}^{2}+\sum_{i=1}^{p} \beta_{i} h_{t-i},
$$

where $\omega>0, \alpha_{i} \geq 0, \beta_{i} \geq 0$ for all $i$. The unconditional variance of $\varepsilon_{t}$ is $\sigma^{2}=\omega[1-\alpha(1)-\beta(1)]^{-1}$, where $\alpha(L) \equiv \sum_{i=1}^{q} \alpha_{i} L^{i}$ and $\beta(L) \equiv \sum_{i=1}^{p} \beta_{i} L^{i}$ and $\alpha(1)+\beta(1)<1$ is required.

Several interesting aspects of GARCH models are noteworthy. First, although the innovations in a series are serially uncorrelated, they are not independent because of the dependence across time of the conditional second moments. Second, large innovations in the process will cause an increase in the conditional variance, but forecasts of the future conditional variances will damp down toward the unconditional value. Such a property is desirable in exchange rate modelling since, as Frenkel and Levich (1977) noted, foreign exchange markets are characterized by tranquil and turbulent periods. A third property that is desirable for asset prices in general and exchange rates in particular is that the fourth unconditional moment of $\varepsilon_{t}$ will exceed $3 \sigma^{4}$. Hence, the unconditional distribution of $\varepsilon_{t}$ will be leptokurtic relative to the normal distribution.

One feature of GARCH models that is not attractive is the assumption that the conditional variance can be modelled as a function of the current information set of the econometrician (except for parameters that must be estimated). This assumption is the simple extension of the usual time series assumption that the model of the conditional mean of the time series is known to the econometrician. Just as it is possible that agents have much better models of the conditional mean of a series than can be obtained by restricting the information set to that of the econometrician, it is also 
quite possible that the true conditional variance that agents use in forecasting and in forming portfolios of assets is quite different from the GARCH specification that is the best given the limited availability of data. The GARCH model imposes strong testable restrictions on the data, and it does provide an estimate of conditional variances. ${ }^{13}$ with this caveat in mind, I turn to the examination of the data.

\section{IV.A. Estimation of Univariate Models with Monthly Data}

An empirical investigation of the model must take a stand on the series to be used to coincide with the theoretical constructs and on the meaning of a period of time. Given the availability of data, I chose the month as the interval for a period, and I examined monthly data for four countries, the United States, the United Kingdom, Japan and West Germany, for the flexible exchange rate era that began with the collapse of the Bretton Woods system in March 1973. The monthly data for each country are the money supply, as measured by Ml, the industrial production index, the consumer price index, and the exchange rate of the country's currency relative to the U.S. dollar. 14

The first step in the identification and estimation of univariate time series models with potentially GARCH innovations was to determine the appropriate degree of differencing for each of the series. The autocorrelations and partial autocorrelations of the levels and first differences of the natural logarithms of the series were examined and in all cases it appeared that first differencing was appropriate to induce stationarity since the autocorrelations of the levels of the series failed to damp significantly. 
This reasoning was supported by examination of Dickey-Fuller tests of the null hypotheses that the level of the series contains a unit root and that there is a unit root in the first differences of the series. If only one unit root is present in the series, the first hypothesis should not be rejected while the second should be rejected. The results of the tests are presented in Table 1 which considers two different alternative hypotheses. The test statistics are constructed by performing ordinary least squares regressions on the following equation either in the presence of a trend or without a trend:

$$
\Delta z_{t}=\alpha_{0}+\alpha_{1} t+\alpha_{2} z_{t-1}+\sum_{i=1}^{3} \alpha_{i+2} \Delta z_{t-i}+\varepsilon_{t},
$$

and $\Delta$ is the first difference operator. If a series $z_{t}$ contains a unit root, a test of the null hypothesis that the coefficient $\alpha_{2}$ in (25) is zero will not be rejected. The ${ }_{{ }_{\mu}}(z)$ and the ${ }_{\tau_{\tau}}(z)$ statistics are the "t-statistics" for the null hypothesis that $\alpha_{2}$ is zero either without a trend in the regression or with a trend, respectively. ${ }^{15}$ Notice that there is only marginal evidence against the hypothesis of a unit root in any of the series and only in the case of the price levels. There is very strong evidence against the hypothesis that the first differences of the series contain a second unit root. These tests are the $\tau_{\mu}(\Delta z)$ and $\tau_{\tau}(\Delta z)$ statistics.

Based on the autocorrelations of the natural logarithms of the series and their first differences and on the Dickey-Fuller tests, I worked with the first differences of the series and estimated simple models. Residual diagnostics were examined to determine if autocorrelation remained in the residuals of the transformed series, and additional models were estimated 
where necessary. The autocorrelations and partial autocorrelations of the squared residuals of the series were then examined to identify a possible GARCH model. This procedure follows the suggestions of Bollerslev (1986), who demonstrates that the autocorrelations and partial autocorrelations of the squared residuals may be used to determine the order of GARCH. The resulting estimated models are presented in Table $2 \mathrm{~A}$ with residual diagnostics presented in Table 2B for the levels of the residuals divided by the square roots of the respective conditional variances and the squared residuals divided by the conditional variances. Of the 120 reported autocorrelation coefficients, the first four lags for the levels and squares of the residuals for 15 series, only four coefficients are significantly different from zero using the asymptotic $1 / \sqrt{ } \mathrm{T}$ test. For a few of the series the Q-statistics for 10 and 20 autocorrelations do indicate that higher order autocorrelations may be significantly different from zero, but these effects appear in most cases to be due to seasonality. 16

The results for the United States indicate that the rates of growth of the money supply and the index of industrial production are well modelled by AR(1) processes with $\mathrm{ARCH}(1)$ innovations. The likelihood ratio (LR) test for no first-order ARCH in the residuals is a chi-square statistic with one degree of freedom. The LR statistic for industrial production has a value of 16.578, which has a marginal level of significance (MLS) smaller than .0001, and the LR statistic for the money supply is 7.174 , with an MLS of .007 . The U.S. rate of inflation is an $\mathrm{AR}(2)$ with $\mathrm{ARCH}(1)$ innovations. The LR test and its MLS in this case are 7.108 and .008 .

For the United Kingdom, the results indicate a random walk with ARCH(1) innovations for the rate of growth of industrial production and an AR(1) for 
the rate of growth of the money supply. For industrial production, the LR test for no first-order ARCH and its MLS are 26.106 and less than .0001 . There is essentially no support for ARCH in the rate of growth of the U.K. money supply. The LR test has a value of .078 , which is associated with an MLS of .78. The U.K. rate of inflation was modelled as an AR(1) with ARCH(1) innovations, although higher order autocorrelations do appear to be statistically different from zero. The LR test for no ARCH in the inflation rate has a value of 23.964 , and its associated MLS is smaller than .0001 . The pound-dollar exchange rate was identified to be a random walk, and the LR test in this case had a value of essentially zero.

For Germany, the results indicate an $\mathrm{MA}(1)$ with $\mathrm{ARCH}(1)$ innovations for the rate of growth of industrial production, and an MA(3) with ARCH(1) innovations for the rate of growth of the money supply. The LR tests and their associated MLS's are 20.268 and less than .0001 for the industrial production index and 6.468 with an MLS of .001 for the money supply. The German rate of inflation appeared to be an $\mathrm{AR}(1)$, and the LR test indicated no first-order ARCH since its value was .926 with an MLS of .336 . The deutsche mark-dollar exchange rate was a random walk, and there was some evidence in support of ARCH innovations since the LR test had a value of 2.774 with an MLS of .096 .

For Japan, the rate of growth of the money supply was modelled as an $A R(2)$. The LR test for first-order ARCH had a value of .014 . The rate of growth of industrial production was estimated to be an MA(3) with ARCH(1) innovations. The value of the IR test in this case was 4.506 , which is associated with an MLS of .034 . The Japanese rate of inflation was found to be an AR(3) with ARCH(1) innovations. The LR test and its MLS in this case 
áre 36.854 and smaller than .0001 . The yen-dollar exchange rate was a random walk with some evidence in support of $\mathrm{ARCH}(1)$ innovations since the value of the LR test was 3.256 with an MLS of .071 .

Maximum likelihood estimation of the models maintains an assumption that the innovations in the series are conditionally normal. This assumption is testable since the distribution of the estimated innovations divided by their estimated standard deviations should be a unit normal. Table 2B reports two test statistics labelled B1 and B2. The statistic B1 is a test of skewness, and it is the ratio of the third sample moment around the sample mean to the second sample moment raised to the $(3 / 2)$ power. The statistic B2 is a test of kurtosis, and it is the ratio of the fourth sample moment to the squared second sample moment.

The assumption of normality of the several of the series appears to be quite questionable given the large values of the tests of skewness and kurtosis reported in Table 2B. The German and U.K. industrial production series appear to be particularly bad in this respect. The exchange rate series are also poorly behaved showing both signs of excess kurtosis and of negative skewness for the yen and the pound.

Two results about the time series processes of the exchange rates are striking in Table 2A. The first is that each currencies rate of depreciation relative to the dollar appears to be serially uncorrelated relative to its past history. This is a common finding. Perhaps the most interesting result of Table $2 \mathrm{~A}$ is the lack of strong evidence of $\mathrm{ARCH}$ in the monthly logarithmic changes in exchange rates. This is in strong contrast to the intuition described earlier and to the findings of conditional heteroscedasticity in studies of risk premiums with monthly data as in Hodrick and Srivastava 
(1984) and Domowitz and Hakkio (1985). Perhaps it is an indication that the ARCH process is not a good economic model of the conditional heteroscedasticity apparently present in the data in other studies.

The finding of no or limited ARCH in the exchange rate data sampled at a monthly interval is also surprising in light of the strong evidence of ARCH in the data sampled at a weekly interval reported in Engle and Bollerslev (1986) and Diebold and Nerlove (1986) and in daily data reported in Baillie and Bollerslev (1987). The next section investigates a time series model of exchange rates with weekly sampling of the data to demonstrate that GARCH is present at that sampling interval.

\section{IV.B. An Exchange Rate Model with Weekly Data}

Table $3 \mathrm{~A}$ provides an investigation of data for seven currencies versus the U.S. dollar that are sampled on each Wednesday from June 13, 1973 to January 23, 1985. The only data that were employed in the model consist of the spot and one month forward exchange rates. The estimated time series model of the rate of depreciation of a currency relative to the U.S. dollar is the following:

$$
\begin{aligned}
s_{t+1}-s_{t} & =b_{0}+b_{1}\left(f_{t}-s_{t}\right)+\left(1-\rho_{1} L-\rho_{2} L^{2}\right)^{-1} \varepsilon_{t+1} \\
\varepsilon_{t+1} \mid \Phi_{t} & \sim N\left(0, h_{t+1}\right) \\
h_{t+1} & =\omega+\alpha \varepsilon_{t}^{2}+\beta h_{t}+\delta\left(f_{t}-s_{t}\right)^{2} .
\end{aligned}
$$

In (26a) the forward premium is used in the model of the conditional mean of the rate of depreciation and in (26c) the squared forward premium is used in the model of the conditional variance of the rate of depreciation. 17

The presence of the forward premium in the conditional mean of the rate 
of depreciation has a long history in international finance, and the presence of several negative estimated coefficients on the forward premium, the $b_{1}{ }^{\prime} s$, is consistent with the results of Fama (1984) and others. Whether this is valid evidence of variation in risk premiums that is greater than variation in expected rates of depreciation is a matter of considerable debate. ${ }^{18}$ Five of the currencies also show slight evidence of residual serial correlation that can be exploited in forecasting the conditional mean of the series.

The comparatively new aspect of Table $3 \mathrm{~A}$ is the presence of the squared forward premium in the conditional variance. The tests of conditional heteroscedasticity conducted by Cumby and Obstfeld (1984) and Hodrick and Srivastava (1984) indicated that such a variable ought to be present, and it enters significantly in four of the seven currencies.

Table 3B reports a large number of LR tests of the model. These tests are not all independent, and consequently, some care ought to be taken in considering the results of the tests. Usually, the results are so strong that reducing the marginal level of significance required to reject the null hypothesis under consideration because of the large number of tests would have no influence on inference. I report the IR tests with their associated marginal levels of significance in parenthesis.

There is exceedingly strong evidence of GARCH as evidenced by the test of $\alpha=0$ and $\beta=0$ in row 3 . The LR statistics range from $34.092(<.0001)$ for the British pound to 230.242 (<.0001) for the Italian lira. ${ }^{19}$ The evidence for the importance of the squared forward premium in the conditional variance is not as striking, but it seems safe to reject the hypothesis of no effect given the LR test statistics of 19.788 (<.0001) for the Deutsche mark, $11.768(.001)$ for the Swiss franc, 5.518 (.019) for the French franc, and 
$8.830(.003)$ for the Japanese yen.

The null hypothesis in row 5 of Table $3 B$ considers the evidence against the hypothesis of no time variation in the conditional mean of the rate of depreciation $\left(b_{1}=\rho_{1}=\rho_{2}=0\right)$. The LR tests are chi-square statistics with three degrees of freedom in this case, and it appears safe to reject the hypothesis for the Deutsche mark, 18.808 (<.0001), the Swiss franc, 7.946 (.019), the French franc, 17.402 (.001), the Japanese yen, 13.064 (.005), and the British pound, $10.912(.004)$.

\section{IV.C. Tests of the Theory}

The previous sections established the presence of movements in the conditional variances of some of the exogenous processes of the model, and it remains to examine whether changes in these conditional variances are associated with changes in the exchange rate as is predicted by the theory. An initial investigation for the possibility of these effects is conducted in this section.

The best way to test the theory would be to conduct maximum likelihood estimation of the equations for the exchange rate and other asset prices subject to the restrictions of the theory while simultaneously estimating the laws of motion for the driving processes. These laws of motion would include the specifications of the conditional variances and covariances of the exogenous processes. Such an estimation strategy is certainly feasible, but it is quite complicated. Instead, I conduct a preliminary investigation of the data, under a set of restrictive assumptions, in order to determine how well some simple ideas work empirically. The goal of this section is therefore to conduct such a limited empirical investigation in order to 
determine whether more adventuresome estimation ought or needs to be undertaken.

I employ the following two-stage strategy. I first estimate the conditional variances with the ARCH procedure discussed above, and second, I estimate an exchange rate equation with ordinary least squares (OLS) using the presumed exogenous data on monies and industrial productions and their estimated conditional variances from the first stage.

Pagan (1984, Theorem 12) examines the consistency and the asymptotic distribution of such a strategy. He demonstrates that if the first stage estimation produces consistent estimates of the conditional variances used by agents, the two-stage procedure will produce consistent estimates of the true parameters of interest. The ARCH estimates will be consistent estimates of the true conditional variances under the assumptions that the true process is a univariate ARCH model, and agents are rational and use the same model. If agents actually use a larger information set than the econometrician in forecasting the conditional means or the conditional variances of the exogenous series, the ARCH estimates are unlikely to be consistent estimates of the true conditional variances. Unfortunately, in the more likely case that the conditional variances estimated in the ARCH framework are not truth, the procedure employed here will be inconsistent.

Pagan also demonstrates that if the estimated conditional variances are consistent, the OLS estimates of the standard errors of the parameter estimates in the second stage will understate the true standard errors. Hence, failure to reject the hypothesis of zero influence of the explanatory variables cannot be reversed by calculation of the appropriate standard errors. In this respect the procedure that I have taken is a simple yet 
appropriate first step in determining the validity of the model, subject to the caveat that the ARCH estimates may not be consistent estimates of the truth.

Since there is strong evidence that the levels of the natural logarithms of exchange rates contain a unit root, I first differenced equation (18), and examined the following specification with ordinary least squares:

$$
\begin{aligned}
\Delta \mathrm{s}_{\mathrm{t}}=\beta_{0} & +\beta_{1} \Delta \mathrm{h}_{1 \mathrm{t}}+\beta_{2} \Delta \mathrm{h}_{2 \mathrm{t}}+\beta_{3} \Delta \mathrm{h}_{3 \mathrm{t}}+\beta_{4} \mathrm{~h}_{4 \mathrm{t}}+\beta_{5} \Delta \mathrm{m}_{1 \mathrm{t}} \\
& +\beta_{6} \Delta \mathrm{m}_{2 t}+\beta_{7} \Delta \mathrm{y}_{1 \mathrm{t}}+\beta_{8} \Delta \mathrm{y}_{2 \mathrm{t}}+\beta_{9} \Delta \omega_{1 \mathrm{t}}+\beta_{10} \Delta \omega_{2 t}+\varepsilon_{\mathrm{t}}
\end{aligned}
$$

where $\Delta$ is the first difference operator. The specification of (27) requires an explanation of the error term. Under a tight interpretation of the theory, the error term in (27) is the first difference in the expected shares of government spending in the two economies. These variable were assumed to be exogenous and independent of the right-hand-side variables included in (27). Hence, ordinary least squares is appropriate.

Such a tight interpretation of the theory is no doubt inappropriate since the assumed time series processes of the exogenous variables that led to the specification of (18) as the solution of the model were in most cases not supported in the empirical investigation. This is particularly true of the industrial production series that were treated in the theory section as stationary in levels while in the empirical section they were found to contain unit roots. The effect of solving the model with the estimated rather than the assumed processes would be to add the first differences of the rates of growth of industrial production to the list of explanatory variables and to increase the lag length of the included variable in cases where moving average processes or higher order AR processes were identified.

The results in Table 4 indicate that the data do not provide much 
support for the theory. The right-hand-side variables are essentially unrelated to changes in exchange rates. The studies of Meese and Rogoff (1983a, 1983b, 1986) and other studies in the tradition of the monetary approach to the determination of the exchange rate have conditioned our response to the failure of money and industrial production to explain exchange rates such that this finding is not particularly surprising. Unfortunately, the conditional variances of the exogenous processes as measured by the ARCH models, also are not capable of explaining changes in exchange rates.

In the next section I explore some ideas for exchange rate determination that may be more fruitful than the current exercise.

\section{Conclusions}

The purpose of this paper was to develop a model of exchange rate determination that could provide some new directions for empirical work in the area by focusing on the way changes in the uncertainties in the economic environment interact with the risk aversion of economic agents to produce changes in asset prices. While the initial empirical investigation of the theory has not been very supportive of the model, there are some additional avenues of investigation that ought to be tried before the model is discarded. In this section I discuss some of the directions that could be taken, and I offer some additional ideas about the development of theoretical models that could allow them to achieve more consistency with the data.

We know that changes in nominal exchange rates are highly correlated with changes in real exchange rates, and that these changes in real exchange rates are highly persistent. ${ }^{20}$ One of the roles of the government spending 
variables in the theory part of the paper was to provide policy variables that were potentially responsible for persistent changes in real exchange rates. I have not attempted to test this implication of the theory, and attempting to develop tests of this implication should be a challenging yet exciting exercise.

Another challenging area for new research is the development and estimation of alternative models of the conditional variances of monies, incomes and other variables that I have treated as exogenous, other than the formulation of GARCH models. Although such models may be good summaries of the serial dependence in a given data series, two problems are apparent. First, the estimates may be quite poor estimates of the true conditional variances. The resulting errors-in-variables problems that arise in the estimation make it difficult to derive consistent estimators of the influence of the true conditional variances. Second, as economists we would like to know what causes the changes in the conditional variances. Since univariate ARIMA models have proven useful in developing atheoretical forecast of economic time series, we can expect similar success for GARCH models of conditional second moments. Nevertheless, the Lucas (1976) critique serves as a warning that we should look deeper into the economy than the capabilities of such time series models if we are going to be concerned about the policy implications of our models or about our ability to forecast when there are changes in policy regimes.

The theoretical model has implications for many asset prices other than exchange rates, and it would be interesting to test the restrictions of the model in several asset markets simultaneously. The determination of the nominal interest rates and the risk premiums in forward market and in stock 
markets are all candidates that might be examined with alternative empirical models of conditional variances. One serious problem in conducting these investigations that ought to be kept in mind is the peso problem. In Hodrick (1987) I examine many models of risk premiums in the forward and futures foreign exchange markets. An alternative interpretation of the apparent variability of risk premiums is the existence of peso problems. If these plague the forward market, they also plague the spot foreign exchange markets and the other asset markets of the world.

A third area of research on the model that may be warranted is the possible influence of time aggregation. Two problems are noteworthy in this area. The first is what is the appropriate time interval to identify as a period in a cash-in-advance model. The second area of concern is the influence of additional sources of information about the relevant exogenous variables. There are many sources of information in an economy about the monthly innovations in monies, incomes, and other economic aggregates and their future values that cause exchange rates to move and are not in the model. How should the analysis be modified to handle such a situation? One potential flaw in the theoretical structure of the model that may deserve investigation is the assumption that international asset markets are complete. Understanding the determination of exchange rates may require the development of models that relax this assumption in a sensible way. By sensible, I do not mean arbitrarily closing asset markets or prohibiting intertemporal trade just to government bonds, but I mean studying the economics of the world economy to determine what assets are traded, in what amounts, why countries periodically prohibit intertemporal trade, and how many claims countries accumulate against each other. 
Footnotes

This research was funded by a grant from The Lynde and Harry Bradley Foundation to whom I express my gratitude for its support. I thank Ian Domowitz, Robert Flood, Milton Harris, Ravi Krishnaswamy, Robert Korajczyk, Deborah Lucas, Rodolfo Manuelli, Robert McDonald, Daniel Siegel, Lars Svensson, and the participants in seminars at the 1987 National Bureau of Economic Research International Studies Summer Institute, Georgetown University, the International Monetary Fund, Northwestern University, and Ohio State University for helpful conversations and suggestions. Special appreciation is extended to Mark Watson for his help in developing Table 1 and especially to Tim Bollerslev for his help in executing the GARCH program and for his assistance in developing Table 3. I also want to thank Patricia Reynolds for efficient and valuable research assistance.

1. Representative models that Meese and Rogoff (1983a, 1983b, 1986) examine are the flexible price monetary models of Bilson (1978), Frenkel (1976), and Hodrick (1978), the sticky-price models of Dornbusch (1976) and Frankel (1979), and the portfolio balance model of Hooper and Morton (1982).

2. Boughton (1986) examines the performance of portfolio balance models in an out-of-sample forecasting experiment and concludes that they perform better than the random walk in some cases.

3. Keim and Stambaugh (1986) document significant variation in a variety of risk premiums including those on common stocks of firms of various sizes, long-term bonds of various default risks, and nominal default-free bonds of various maturities. Campbell (1987) finds that the state of the term structure of interest rates has significant predictive ability for the holding-period excess returns of two-month bills, six-month bills, five to 
ten year bonds, and the value-weighted New York Stock Exchange return, all relative to the one-month bill. Longer term movements in returns on the stock market are examined in Fama and French (1986) and Flood, Hodrick and Kaplan (1986).

4. The extensive empirical literature on the efficiency of forward and futures foreign exchange markets and the relation of the prices in these markets to future spot exchange rates is critically reviewed in Hodrick (1987).

5. Their analyses were motivated by the empirical work of Pindyck (1984), Poterba and Summers (1986), and French, Schwert and Stambaugh (1986). These authors attempt to determine the influence of changes in the variance of returns on the stock market on the required expected rate of return. Barsky (1986) examined the issues in a two-period model.

6. The two endowments can be thought of as the "fruit" of the "trees" that are located only in one country. The trees are the only capital stocks of the countries, and the quantities of each type of tree are fixed and are normalized to one. Sargent (1987) and Manuelli and Sargent (1987) explore several versions of this model.

7. See Judd (1985) for an example of dynamic macroeconomic analysis with a more realistic representation of distortionary taxes on the income of labor and capital.

8. The specification assumes that agents receive no utility from the government spending. Alternative assumptions would substantively affect the equilibrium.

9. The Inada conditions require that the ratio of the marginal utility of good one to the marginal utility of good two goes to zero when the 
consumption of good one goes to infinity, holding the consumption of good two constant, and the same ratio goes to infinity when the consumption of good two goes to infinity, holding the consumption of good one constant. Some of both goods is desired when their prices are positive. 10. Townsend (1987) argues that disparities between the marginal utility of consumption and the marginal utility of wealth induced in models with explicit monetary technologies may help to resolve asset pricing anomalies. Other formulations of cash-in-advance constraints have been explored by Lucas (1984) and Lucas and Stokey (1983, 1987).

11. Svensson (1985) studies the solution only for the case in which the exogenous processes are independently and identically distributed, and he derives the complete characterization of the equilibrium which in general involves times when the value of the multiplier is zero.

12. Engle and Bollerslev (1986) and its associated comments provide a nice introduction to the rapidly expanding econometric and empirical literature associated with models of ARCH and GARCH errors. I am grateful to Tim Bollerslev for sharing his computer program that was used in the identification and estimation of the ARCH models reported in this section. 13. Engle (1982) notes that ARCH effects may arise from misspecification of the model, either through omitted variables or structural change. He argues that ARCH effects may be a better approximation to reality than the assumption of conditional homoscedasticity, but he notes that trying to find the correct model would be superior.

14. The data were obtained from a tape of the International Financial Statistics of the International Monetary Fund and are described in detail in the data appendix. I made no attempt to measure the share of government 
spending in the economies. Some monthly data are available for this series for Germany and the United States, but not for Japan and the United Kingdom. 15. The statistics are not distributed as Student's $t$ distribution in the presence of a unit root. Dickey (1976) tabulated the distributions using Monte Carlo methods and the tables are reported in Fuller (1976). The order of the autoregression (3) was chosen a priori under the hypothesis that this would remove most autocorrelation.

16. Several of the series are available only in seasonally adjusted data. If a series contained significant autocorrelations at seasonal lags, the series was first regressed on seasonal dummy variables and the reported results refer to the residuals from these regressions. Details are in the Data Appendix .

17. The data in Table 2 are from Data Resources Inc. and are described more fully in the Data Appendix.

18. Froot and Frankel (1986) use measurements of forecasts of exchange rates from several sources to address the issue of the degree of variation in expected rates of depreciation and in risk premiums. Their conclusion is that the variability in expected rates of depreciation is larger than the variability of risk premiums.

19. It would be interesting to aggregate the weekly model into changes over a month to determine the consistency of the finding of strong evidence of GARCH innovations for weekly changes in exchange rates with weak evidence of GARCH innovations in monthly changes in exchange rates. 20. See Huizinga (1987) for an analysis of the persistence of changes in real exchange rates. The statistics in the paper indicate that very high order autocorrelations of changes in exchange rates may be sufficiently negative to 
make the real exchange rate a stationary series, but without much more data, it is difficult to rule out a random walk. In any case, the degree of persistence is very long. 


\section{Appendix}

In the first part of this appendix I verify the claim that an increase in the conditional variance of government spending, when it is uniformly distributed, increases $\Xi_{1 t} \equiv \ln \left(E_{t}\left[\left(1-\xi_{1 t+1}\right)^{-\gamma}\right]\right\}$. I reproduce (19a) as (A1) $\Xi_{1 t}=\ln \left\{\left[-\left(1-\mu_{1 t}-h_{5 t}\right)^{1-\gamma}+\left(1-\mu_{1 t}+h_{5 t}\right)^{1-\gamma}\right] /(1-\gamma) 2 h_{5 t}\right\}$, Let $G(\xi) \equiv(1-\xi)^{-\gamma}$, which is an increasing convex function over the relevant range $0 \leq \xi \leq 1$. The derivative of $\Xi_{1 t}$ with respect to $h_{5 t}$ is monotonically related to the derivative of $E_{t}\left[G\left(\xi_{1 t+1}\right)\right]$ which is

$$
\left(1 / h_{5 t}\right)\left\{(1 / 2)\left[\left(1-\mu_{1 t}-h_{5 t}\right)^{-\gamma_{+}}\left(1-\mu_{1 t}+h_{5 t}\right)^{-\gamma}\right]-E_{t}\left[G\left(\xi_{1 t+1}\right)\right]\right\}
$$

The interior of the braces in (A2) is

$$
(1 / 2)\left[G\left(\mu_{1 t}-h_{5 t}\right)+G\left(\mu_{1 t}+h_{5 t}\right)\right]-E_{t}\left[G\left(\xi_{1 t+1}\right)\right]
$$

where $\xi_{1 t+1}$ is uniformly distributed on $\left[\mu_{1 t}-h_{5 t}, \mu_{1 t}+h_{5 t}\right]$. Hence, it must be demonstrated that the average of a convex function evaluated at the end points of the distribution is greater than the expected value of the function. To simplify the proof, I drop time subscripts and let $\xi$ be distributed unifromly on $[a, b]$.

Convexity of $G(\xi)$ implies that $G^{\prime}(\xi)<[G(b)-G(\xi)] /(b-\xi) \forall \xi<b$. Hence, $G(\xi)<G(b)-(b-\xi) G^{\prime}(\xi)$. Integration of both sides gives

$$
\begin{aligned}
& (b-a) E[G(\xi)]<G(b)(b-a)-b[G(b)-G(a)]+\int_{a}^{b} \xi G^{\prime}(\xi) d \xi \text {, and } \\
& \int_{a}^{b} \xi G^{\prime}(\xi) d \xi=b G(b)-a G(a)-(b-a) E[G(\xi)] .
\end{aligned}
$$

Substituting (A5) into (A4) and collecting terms provides the required result in (A3) that $E[G(\xi)]<(1 / 2)[G(b)-G(a)]$. 
Data Appendix

All monthly data were obtained from two tapes of the International Financial Statistics of the International Monetary Fund supplied to Northwestern University by the Inter-university Consortium for Political and Social Research. All of the data except the Japanese price index were taken from tape number ICPSR 7629. The data series begin in March 1973 and end either in January, February, or March 1987 depending on the series. There are between 166 and 168 observations per series. The observations on the Japanese price index were taken from a prevoius ICPSR tape because I discovered a problem with the data on tape 7629 .

The industrial production index is series $66 . \mathrm{c}$, "Industrial Production, Seasonally Adjusted;" these indexes are compiled from reported versions of national indexes.

The price index is series 64, "Consumer Prices;" these indexes are compiled in the same way as are the industrial production indexes.

The money aggregate is series 34, "Money;" this is the sum of currency outside banks and private sector demand deposits, plus (where applicable) private sector demand deposits with the postal checking system and the Treasury. This is an end of month series.

The exchange rate is series ae, "Market Rate/Par or Central Rate;" this is the foreign currency unit value of the U.S. dollar which was quoted on the last trading day of each month.

Seasonal dummy variables were used with the four money supply series and the price indexes other than the U.S. series.

The data in Table 3 were obtained from Data Resources, Inc. The data are bid prices for spot and one month forward exchange rates. 


\section{References}

Abel, Andrew B., 1986, Stock prices under time-varying dividend risk: An exact solution in an infinite-horizon general equilibrium model, Mimeo. (The Wharton School, University of Pennsylvania, Philadelphia, PA).

Baillie, Richard and Tim Bollerslev, 1987, The story of daily exchange rates:

A conditional variance tale, Mimeo. (Northwestern University, Evanston, IL).

Barsky, Robert B., 1986, Why don't the prices of stocks and bonds move together? National Bureau of Economic Research Working Paper No. 2047.

Bilson, John F. 0., 1978, Rational expectations and the exchange rate, in: Jacob A. Frenkel and Harry G. Johnson, eds., The economics of exchange rates (Addison-Wesley, Reading, MA) 75-96.

Bilson, John F. O., 1979, The deutsche mark/dollar rate: A monetary analysis, in: Karl Brunner and Allan H. Meltzer, eds., Policies for employment, prices and exchange rates, Volume 11, Carnegie-Rochester Conference Series on Public Policy (North-Holland, Amsterdam) 59-101.

Bollerslev, Tim, 1986, Generalized autoregressive conditional heteroskedasticity, Journal of Econometrics 31, 307-328.

Boughton, James M., 1986, Tests of the performance of reduced-form exchange rate models, Journal of International Economics, forthcoming.

Campbe11, John Y., 1987, Stock returns and the term structure, Journal of Financial Economics 18, 373-399. 
Cumby, Robert and Maurice Obstfeld, 1984, International interest-rate and price-level linkages under flexible exchange rates: A review of recent evidence, in: John F.O. Bilson and Richard Marston (eds.), Exchange rates: Theory and practice. (University of Chicago Press, (hicago).

Dickey, David A., 1976, Hypothesis testing for nonstationary time series, unpublished Ph.D. dissertation, Iowa State University. Diebold, Francis X. and Marc Nerlove, 1986, The dynamics of exchange rate volatility: A multivariate latent factor ARCH model, Board of Governors of the Federal Reserve System, Division of Research and Statistics, Special Studies Paper No. 205.

Domowitz, Ian and Craig S. Hakkio, 1985, Conditional variance and the risk premium in the foreign exchange market, Journal of International Economics 19, 47-66.

Dornbusch, Rudiger, 1976, Expectations and exchange rate dynamics, Journal of Political Economy 84, 1161-1176.

Engle, Robert F. and Tim Bollerslev, 1986, Modelling the persistence of conditional variances, Econometric Reviews 5, 1-50.

Fama, Eugene F., 1984, Forward and spot exchange rates, Journal of Monetary Economics 14, 319-38.

Fama, Eugene F. and Kenneth R. French, 1986, Permanent and temporary components in stock prices, Mimeo. (University of Chicago, Chicago).

Flood, Robert P., 1987, International asset pricing in general equilibirum, Mimeo. (Northwestern University, Evanston, IL). 
Flood, Robert P., Robert J. Hodrick and Paul Kaplan, 1986, An evaluation of recent evidence on stock market bubbles, National Bureau of Economic Research Working Paper No. 1971.

Frankel, Jeffrey A., 1979, On the mark: A theory of floating exchange rates based on real interest differentials, American Economic Review 69, 610623.

Frankel, Jeffrey A., 1986, The implications of mean-variance optimization for four questions in international macroeconomics, Journal of International Money and Finance 5, \$53-\$76.

Franke1, Jeffrey A. and Richard Meese, 1987, Are exchange rates excessively variable? National Bureau of Economic Research Working Paper No. 2249.

French, Kenneth R., G. William Schwert and Robert F. Stambaugh, 1986, Expected stock returns and volatility, Mimeo. (University of Chicago, (hicago).

Frenke1, Jacob A., 1976, The monetary approach to the exchange rate: Doctrinal aspects and empirical evidence, Scandinavian Journal of Economics 78, 200-224.

Frenke1, Jacob A. and Richard M. Levich, 1977, Transaction costs and interest arbitrage: Tranquil versus turbulent periods, Journal of Political Economy 86, 1209-1226.

Froot, Kenneth A. and Jeffrey A. Franke1, 1986, Interpreting tests of forward discount bias using survey data on exchange rate expectations, Mimeo. (Massachusetts Institute of Technology, Cambridge, MA)

Fuller, Wayne A., 1976, Introduction to statistical time series, (John Wiley and Sons, New York). 
Giovannini, Alberto, 1987, Uncertainty and liquidity, Mimeo. (Graduate School of Business, Columbia University, New York).

Hodrick, Robert J, 1978, An empirical analysis of the monetary approach to the determination of the exchange rate, in: Jacob A. Frenkel and Harry G. Johnson, eds., Studies in the Economics of Exchange Rates, (Addison-Wesley, Reading, MA) 97-116.

Hodrick, Robert J., 1987, The empirical evidence on the efficiency of forward and futures foreign exchange markets (Harwood Academic Publishers, Chur, Switzerland).

Hodrick, Robert J. and Sanjay Srivastava, 1984, An investigation of risk and return in forward foreign exchange, Journal of International Money and Finance $3,1-29$.

Hodrick, Robert J. and Sanjay Srivastava, 1986, The covariation of risk premiums and expected future spot exchange rates, Journal of International Money and Finance 5, S5-S22.

Hooper, Peter, and John E. Morton, 1982, Fluctuations in the dollar: A model of nominal and real exchange rate determination, Journal of International Money and Finance 1, 39-56.

Huizinga, John, 1987, An empirical investigation of the long run behavior of real exchange rates, in: Karl Brunner and Allan H. Meltzer, eds., Carnegie-Rochester Conference Series on Public Policy, Volume 27, forthcoming.

Judd, Kenneth L., 1985, Short-run analysis of fiscal policy in a simple perfect foresight model, Journal of Political Economy 93, 298-319. Keim, Donald B. and Robert F. Stambaugh, 1986, Predicting returns in the stock and bond markets, Journal of Financial Economics 17, 357-390. 
Lucas, Robert E. Jr., 1976, Econometric policy evaluation: A critique," in: Karl Brunner and Allan H. Meltzer, eds., The Phillips Curve and Labor Markets, Carnegie-Rochester Conference Series on Public Policy, Volume $1,19-46$.

Lucas, Robert E. Jr., 1978, Asset pricing in an exchange economy, Econometrica $46,1429-1445$.

Lucas, Robert E. Jr., 1982, Interest rates and currency prices in a twocountry world, Journal of Monetary Economics, 10, 335-360.

Lucas, Robert E. Jr., 1984, Money in a theory of finance, in: Kar1 Brunner and Allan H. Meltzer, eds., Essays on Macroeconomic Implications of Financial and Labor Markets and Political Processes, Carnegie-Rochester Conference Series on Public Policy, Volume 21, 9-45.

Lucas, Robert E. Jr., and Nancy L. Stokey, 1983, Optimal fiscal and monetary policy in an economy without capital, Journal of Monetary Economics 12, 55-93.

Lucas, Robert E. Jr., and Nancy L. Stokey, 1987, Money and interest in a cash-in-advance economy, Econometrica 55, 491-514.

Manuelli, Rodolfo E. and Thomas J. Sargent, 1987, Exercises in Dynamic Macroeconomic Theory, (Harvard University Press, Cambridge MA). Meese, Richard and Kenneth Rogoff, 1983a, Empirical exchange rate models of the seventies: Do they fit out of sample? Journal of International Economics 14, 3-24.

Meese, Richard and Kenneth Rogoff, 1983b, The out-of-sample failure of empirical exchange-rate models: Sampling error or misspecification? in: Jacob A. Frenkel, ed., Exchange Rates and International Macroeconomics (University of Chicago Press, Chicago). 
Meese, Richard and Kenneth Rogoff, 1986, Was it real? The exchange rateinterest differential relation, 1973-1984, National Bureau of Economic Research Working Paper.

Pagan, Adrian, 1984, Econometric issues in the analysis of regressions with generated regressors, International Economic Review 25, 221-247.

Pearson, E. S. and Heartley, H. 0., 1966, Biometrika tables for statisticians, (Cambridge University Press, Cambridge).

Pindyck, Robert, 1984, Risk, inflation and the stock market, American Economic Review 74, 335-351.

Poterba, James and Lawrence Summers, 1986, The persistence of volatility and stock market fluctuations, American Economic Review 76, 1142-1151.

Sargent, Thomas J., 1987, Dynamic Macroeconomic Theory (Harvard University Press, Cambridge, MA).

Stockman, Alan C. and Lars E. O. Svensson, 1987, Capital flows, investment, and exchange rates, Journal of Monetary Economics 19, 171-202.

Svensson, Lars E. O., 1985a, Currency prices, terms of trade, and interest rates: A general equilibrium asset-pricing cash-in-advance approach, Journal of International Economics 18, 17-42.

Svensson, Lars E. O., 1985b, Money and asset prices in a cash-in-advance economy, Journal of Political Economy 93, 919-944.

Townsend, Robert M., 1987, Asset return anomalies in a monetary economy, Journal of Economic Theory 41, 219-247. 
TABLE 1

DICKEY-FULLER UNIT ROOT TESTS

$$
\Delta z_{t}=\alpha_{0}+\alpha_{1} t+\alpha_{2} z_{t-1}+\sum_{i=1}^{3} \alpha_{i+2} \Delta z_{t-i}+\varepsilon_{t}
$$

\begin{tabular}{lccccc}
\hline Series & Nobs & $\tau_{\mu}(z)$ & $\tau_{T}(z)$ & $\tau_{\mu}(\Delta z)$ & $\tau_{\tau}(\Delta z)$ \\
\hline JY & 168 & -0.337 & -3.227 & $-3.955 *$ & $-4.082 *$ \\
\hline JP & 168 & $-5.721 *$ & $-5.075 *$ & $-4.373 *$ & $-5.948 *$ \\
\hline JM & 167 & -1.870 & -2.772 & $-10.882 *$ & $-11.100 *$ \\
\hline JS & 169 & -0.255 & -1.555 & $-5.030 *$ & $-5.184 *$ \\
\hline GY & 168 & -1.120 & -2.464 & $-6.889 *$ & $-6.897 *$ \\
\hline GP & 169 & $-3.125 * *$ & 0.034 & $-4.361 *$ & $-5.476 *$ \\
\hline GS & 167 & -1.276 & -2.205 & $-11.031 *$ & $-11.072 *$ \\
\hline UKY & 169 & -1.296 & -1.232 & $-5.844 *$ & $-5.867 *$ \\
\hline UKP & 168 & -1.138 & -2.280 & $-6.614 *$ & $-6.676 *$ \\
\hline UKM & 169 & $-4.130 *$ & -0.970 & $-4.370 *$ & $-6.351 *$ \\
\hline UKS & 167 & -1.667 & -1.117 & $-7.449 *$ & $-7.712 *$ \\
\hline USY & 169 & -1.524 & -1.562 & $-5.411 *$ & $-5.439 *$ \\
\hline USP & 169 & -0.893 & -2.816 & $-4.615 *$ & $-4.618 *$ \\
\hline USM & 168 & -1.882 & -0.050 & $-3.243 * *$ & $-3.719 * *$ \\
\hline
\end{tabular}

Notes: The first one or two letters of each series denotes the country ( $\mathrm{J}=$ Japan, $G=$ Germany, $U K=$ United Kingdom, US = United States), and the last letter denotes the economic aggregate $(\mathrm{Y}=$ industrial production, $\mathrm{P}=$ consumer prices, $M=$ money supply, $S=$ spot exchange rate). The DickeyFuller statistics are the ratios of the estimated $\alpha_{2}$ to its standard error in the presence of a trend for $\tau_{\tau}$ and without trend for $\tau_{\mu}$. The critical values for $\tau_{\tau}$ are $-3.41(58)$ and -3.96 (18) and for $\tau_{\mu}$ they are -2.86 (58) and -3.43 (18). Rejection of the null hypothesis of the presence of a unit root in the level of the natural logarithm of the series (z) or its first difference $(\Delta z)$ is indicated by $a *$ at the 18 marginal level of significance or by $* *$ at the 58 marginal level of significance. 
TABLE 2A

UNIVARIATE MODELS

\begin{tabular}{|c|c|c|c|c|c|c|c|}
\hline \multirow{2}{*}{$\begin{array}{r}\text { Series } \\
\text { ARMA } \\
\text { ARCH }\end{array}$} & \multirow{2}{*}{$\begin{array}{l}\text { No. of } \\
\text { Obs. }\end{array}$} & \multicolumn{6}{|c|}{ MODEL } \\
\hline & & CONS. 1 & COEF. 1 & COEF. 2 & COEF. 3 & CONS. 2 & COEF. 4 \\
\hline $\begin{array}{l}\mathrm{JY} \\
\mathrm{MA}(3) \\
\operatorname{ARCH}(1)\end{array}$ & 167 & $\begin{array}{l}.0003 \\
.0013 \\
.8175 \\
\end{array}$ & $\begin{array}{r}-.1867 \\
.0899 \\
.0378 \\
\end{array}$ & $\begin{array}{l}.1890 \\
.0844 \\
.0251 \\
\end{array}$ & $\begin{array}{r}.3133 \\
.0681 \\
<.0001 \\
\end{array}$ & $\begin{array}{r}.00013 \\
.00002 \\
<.0001 \\
\end{array}$ & $\begin{array}{l}.1817 \\
.1212 \\
.1338 \\
\end{array}$ \\
\hline $\begin{array}{l}\mathrm{JP} \\
\mathrm{AR}(3) \\
\mathrm{ARCH}(1)\end{array}$ & 151 & $\begin{array}{r}-.0013 \\
.0008 \\
.1042 \\
\end{array}$ & $\begin{array}{l}.2296 \\
.0945 \\
.0151 \\
\end{array}$ & $\begin{array}{l}.0291 \\
.0572 \\
.6110 \\
\end{array}$ & $\begin{array}{r}.2157 \\
.0507 \\
<.0001 \\
\end{array}$ & $\begin{aligned} .00002 \\
.000005 \\
<.0001 \\
\end{aligned}$ & $\begin{array}{l}.5642 \\
.1927 \\
.0034 \\
\end{array}$ \\
\hline $\begin{array}{l}\mathrm{JM} \\
\mathrm{AR}(2)\end{array}$ & 166 & $\begin{array}{c}-.00003 \\
.00072 \\
.9667 \\
\end{array}$ & $\begin{array}{r}-.4517 \\
.0760 \\
<.0001 \\
\end{array}$ & $\begin{array}{r}-.3580 \\
.0825 \\
<.0001 \\
\end{array}$ & & $\begin{array}{r}.00033 \\
.00003 \\
<.0001 \\
\end{array}$ & \\
\hline $\begin{array}{l}\text { JS } \\
\text { RW } \\
\text { ARCH(1) }\end{array}$ & 168 & $\begin{array}{r}-.0035 \\
.0026 \\
.1782 \\
\end{array}$ & & & & $\begin{array}{r}.00092 \\
.00011 \\
<.0001 \\
\end{array}$ & $\begin{array}{l}.1356 \\
.0786 \\
.0845 \\
\end{array}$ \\
\hline $\begin{array}{l}\text { GY } \\
\text { MA(1) } \\
\operatorname{ARCH}(1)\end{array}$ & 167 & $\begin{array}{l}.00002 \\
.00061 \\
.9738 \\
\end{array}$ & $\begin{array}{c}-.2354 \\
.0817 \\
.004 \\
\end{array}$ & & & $\begin{array}{r}.00024 \\
.00003 \\
<.0001 \\
\end{array}$ & $\begin{array}{l}.2840 \\
.1268 \\
.0251 \\
\end{array}$ \\
\hline $\begin{array}{l}\mathrm{GP} \\
\mathrm{AR}(1)\end{array}$ & 168 & & $\begin{array}{r}.5321 \\
.0683 \\
<.0001 \\
\end{array}$ & & & $\begin{aligned} & .000005 \\
& .0000004 \\
&<.0001 \\
&\end{aligned}$ & \\
\hline $\begin{array}{l}\text { GM } \\
\operatorname{MA}(3) \\
\operatorname{ARCH}(1) \\
\end{array}$ & 166 & $\begin{array}{l}.0005 \\
.0009 \\
.5785 \\
\end{array}$ & $\begin{array}{r}-.1998 \\
.0847 \\
.0188 \\
\end{array}$ & $\begin{array}{l}.0631 \\
.0741 \\
.3944 \\
\end{array}$ & $\begin{array}{r}.3864 \\
.0611 \\
<.0001 \\
\end{array}$ & $\begin{array}{r}.00007 \\
.00001 \\
<.0001 \\
\end{array}$ & $\begin{array}{l}.3932 \\
.1482 \\
.008 \\
\end{array}$ \\
\hline $\begin{array}{l}\text { GS } \\
\text { RW }\end{array}$ & 168 & $\begin{array}{r}-.0028 \\
.0026 \\
.2815 \\
\end{array}$ & & & & $\begin{array}{r}.00123 \\
.00011 \\
<.0001 \\
\end{array}$ & \\
\hline $\begin{array}{l}\text { UKY } \\
\text { RW } \\
\text { ARCH(1) }\end{array}$ & 167 & $\begin{array}{l}.0023 \\
.0010 \\
.0214 \\
\end{array}$ & & & & $\begin{array}{r}.00015 \\
.00002 \\
<.0001 \\
\end{array}$ & $\begin{array}{r}.6651 \\
.1648 \\
<.0001 \\
\end{array}$ \\
\hline $\begin{array}{l}\text { UKP } \\
\operatorname{AR}(1) \\
\operatorname{ARCH}(1)\end{array}$ & 168 & $\begin{array}{r}-.0013 \\
.0013 \\
.3173 \\
\end{array}$ & $\begin{array}{r}.6350 \\
.0849 \\
<.0001 \\
\end{array}$ & & & $\begin{array}{l}.00002 \\
.000002 \\
<.0001 \\
\end{array}$ & $\begin{array}{r}.3651 \\
.0833 \\
<.0001 \\
\end{array}$ \\
\hline $\begin{array}{l}\mathrm{UKM} \\
\mathrm{AR}(1)\end{array}$ & 166 & $\begin{array}{c}-.00003 \\
.00083 \\
.9712 \\
\end{array}$ & $\begin{array}{r}-.1881 \\
.0767 \\
.0142 \\
\end{array}$ & & & $\begin{array}{r}.00024 \\
.00002 \\
<.0001 \\
\end{array}$ & \\
\hline $\begin{array}{r}\text { UKS } \\
\text { RW }\end{array}$ & 168 & $\begin{array}{l}.0030 \\
.0026 \\
.2486 \\
\end{array}$ & & & & $\begin{array}{r}.00098 \\
.00009 \\
<.0001 \\
\end{array}$ & \\
\hline $\begin{array}{l}\text { USY } \\
\operatorname{AR}(1) \\
\operatorname{ARCH}(1)\end{array}$ & 168 & $\begin{array}{l}.0036 \\
.0013 \\
.0056 \\
\end{array}$ & $\begin{array}{r}.5055 \\
.0674 \\
<.0001 \\
\end{array}$ & & & $\begin{aligned} & .00005 \\
& .000005 \\
&< .0001 \\
&\end{aligned}$ & $\begin{array}{l}.3089 \\
.1261 \\
.0143 \\
\end{array}$ \\
\hline $\begin{array}{l}\text { USP } \\
\text { AR(2) } \\
\text { ARCH(1) }\end{array}$ & 167 & $\begin{array}{r}.0057 \\
.0006 \\
<.0001 \\
\end{array}$ & $\begin{array}{r}.5510 \\
.0870 \\
<.0001 \\
\end{array}$ & $\begin{array}{l}.1653 \\
.0830 \\
.0464 \\
\end{array}$ & & $\begin{array}{r}.000006 \\
.000001 \\
<.0001 \\
\end{array}$ & $\begin{array}{l}.3015 \\
.2044 \\
.1402 \\
\end{array}$ \\
\hline $\begin{array}{l}\text { USM } \\
\text { AR (1) } \\
\text { ARCH (1) }\end{array}$ & 168 & $\begin{array}{r}-.0001 \\
.0009 \\
.9115 \\
\end{array}$ & $\begin{array}{l}.2456 \\
.0908 \\
.0068 \\
\end{array}$ & & & $\begin{array}{c}.00003 \\
.000004 \\
<.0001 \\
\end{array}$ & $\begin{array}{l}.2705 \\
.1354 \\
.0457 \\
\end{array}$ \\
\hline
\end{tabular}


univariate ARMA model and "CONS.2" refers to the estimated constant in the ARCH mode1. "COEF.1-3" are the estimated AR or MA coefficients, "COEF.4" is the estimated ARCH coefficient. The first number listed in each cell under the "MODEL" section is the coefficient estimate, and the second is the associated standard error. The third is the MLS for $\mathrm{H}_{0}$ : coefficient = $0 ; "<.0001 "$ implies that the MLS is less than .0001. A blank cell implies that the corresponding term does not enter into the series specification. 
TABLE 2B

RESIDUAL DIANOSTICS OF THE UNIVARIATE MODELS

\begin{tabular}{lcrrrrrrr}
\hline \multirow{2}{*}{ SERIES } & \multirow{2}{*}{ B1 } & \multirow{2}{*}{ B2 } & $\rho 1$ & $\rho 2$ & $\rho 3$ & $\rho 4$ & Q(10) & Q(20) \\
& & & & & & & & \\
\hline JY & -0.065 & \multirow{2}{*}{3.333} & -.003 & .047 & .057 & -.073 & 13.828 & 39.294 \\
& & & .021 & -.107 & .077 & -.049 & 7.353 & 15.090 \\
\hline JP & 0.229 & 2.645 & -.047 & .019 & .078 & .004 & 9.537 & 21.817 \\
& & & -.044 & .038 & .059 & .049 & 18.275 & 30.338 \\
\hline JM & 0.405 & \multirow{2}{*}{3.860} & .038 & .008 & .066 & .004 & 26.179 & 33.022 \\
& & &. .008 & -.048 & -.012 & -.074 & 3.102 & 10.581 \\
\hline JS & -0.437 & \multirow{2}{*}{3.763} & .067 & .067 & .138 & .092 & 9.671 & 19.933 \\
& & & .023 & .055 & .047 & .132 & 13.010 & 21.872 \\
\hline GY & -1.016 & 6.993 & -.080 & -.059 & .197 & -.041 & 15.064 & 26.736 \\
& & & .055 & -.042 & .014 & -.026 & 2.755 & 10.141 \\
\hline GP & 0.784 & 4.228 & -.069 & -.004 & .142 & .069 & 14.041 & 34.106 \\
& & &. .063 & -.086 & .003 & .008 & 3.511 & 9.850 \\
\hline GM & 0.140 & \multirow{2}{*}{0.849} & .014 & -.032 & .028 & -.002 & 11.552 & 35.333 \\
& & & -.038 & -.073 & .058 & -.079 & 10.273 & 17.079 \\
\hline GS & -0.171 & 4.027 & -.006 & .137 & .004 & .008 & 8.188 & 17.689 \\
& & & .145 & -.026 & -.047 & -.032 & 5.179 & 13.867 \\
\hline UKY & -0.513 & 6.944 & -.046 & -.098 & .005 & .047 & 5.938 & 17.981 \\
& & & -.013 & .108 & .050 & -.068 & 5.684 & 8.247 \\
\hline UKP & 1.268 & 6.204 & -.050 & -.037 & .230 & -.010 & 26.881 & 44.392 \\
& & & .010 & -.020 & .121 & -.060 & 14.815 & 18.032 \\
\hline UKM & 0.358 & 3.947 & .007 & .048 & .067 & .009 & 10.632 & 16.804 \\
& & & .017 & -.080 & .043 & .192 & 11.564 & 16.897 \\
\hline UKS & -0.619 & 4.541 & .036 & .108 & -.034 & .076 & 6.149 & 21.120 \\
& & & -.005 & -.041 & -.038 & .284 & 14.951 & 18.312 \\
\hline USY & 0.025 & 4.473 & -.013 & .050 & .087 & .082 & 5.444 & 14.778 \\
& & & .039 & -.113 & -.027 & .066 & 5.088 & 21.472 \\
\hline USP & 0.275 & 4.970 & -.033 & -.078 & .054 & .074 & 12.603 & 40.723 \\
& & & -.006 & -.052 & -.003 & -.055 & 4.270 & 5.795 \\
\hline USM & 0.080 & 3.146 & .004 & -.105 & .151 & -.121 & 24.500 & 41.851 \\
& & & .024 & -.150 & .054 & .134 & 15.423 & 30.670 \\
\hline & & & & & & &
\end{tabular}

Notes: See also Table 2A. The statistic $B 1=m_{3} /\left(m_{2}\right)^{(3 / 2)}$ is a test of skewness, (where $m_{i}$ denotes the $i$ th moment of the sampled population); and the statistic B2 $=\mathrm{m}_{4} /\left(\mathrm{m}_{2}\right)^{2}$ is a test of kurtosis for $\varepsilon_{t} / \sqrt{ } \mathrm{h}_{t}$. Under the null hypothesis of a normal distribution for the population, the $5 \%$ critical value for $\mathrm{H}_{0}$ : no skewness, is 0.299 , and the 58 critical value for $\mathrm{H}_{0}$ : normal kurtosis, is 3.63, [see Pearson and Hartley (1966)]. The first four estimated autocorrelation coefficients are denoted $\rho 1-\rho 4$ for $\varepsilon_{t} / \sqrt{ } h_{t}$ (first line) and for $\varepsilon_{t}^{2} / h_{t}$ (second line). The 58 critical value for $H_{0}: \rho i$ $=0$ is .154. $Q(10)$ and $Q(20)$ are the corresponding Ljung-Box statistics; 5 c critical values for $\mathrm{H}_{0}$ : no autocorrelation at 10 or 20 lags are 18.307 and 31.410 , respectively. 
TABLE 3A

MODELS OF EXCHANGE RATES WITH WEEKLY OBSERVATIONS

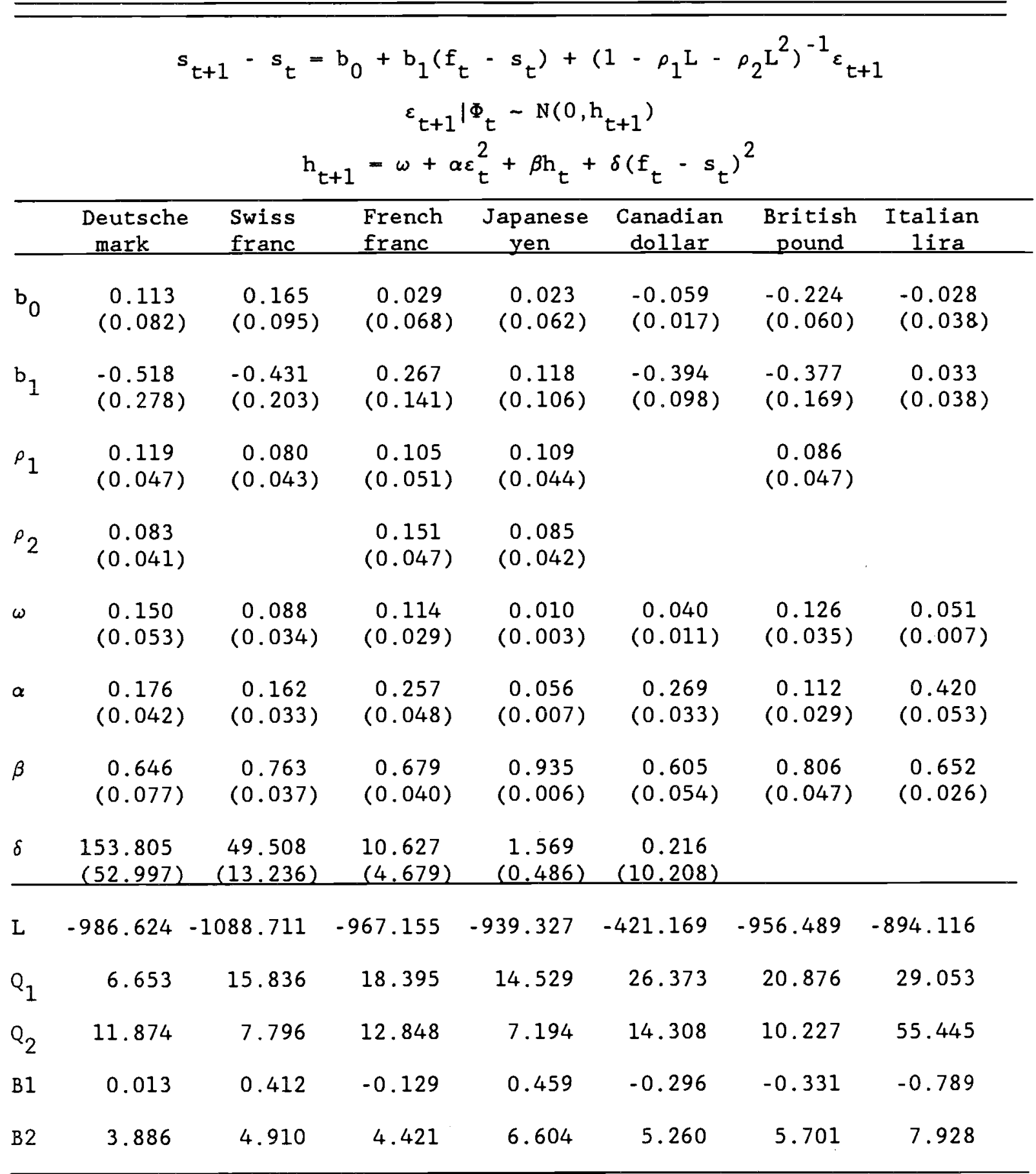

Notes: See also Table 2. The data are sampled weekly on Wednesdays for June 13, 1973 to January 23, 1985 for 607 observations. The logarithmic differences are multiplied by 100 . The $\log$ likelihood function is $L . Q_{1}$ is the chi-square statistic for testing the significance of the first fifteen autocorrelations of $\varepsilon_{f}, Q_{2}$ is the analogous statistic for $\varepsilon_{t}$. The $5 \%$ critical values are 0.099 for B1 and 3.199 for B2. 
TABLE 3B

LIKELIHOOD RATIO TESTS OF MODELS IN TABLE 3A

Nul1 Hypothesis

Test Statistics

\begin{tabular}{|c|c|c|c|c|c|c|c|}
\hline & $\begin{array}{l}\text { Deutsche } \\
\text { mark }\end{array}$ & $\begin{array}{l}\text { Swiss } \\
\text { franc } \\
\end{array}$ & $\begin{array}{l}\text { French } \\
\text { franc }\end{array}$ & $\begin{array}{c}\text { Japanese } \\
\text { yen }\end{array}$ & $\begin{array}{c}\text { Canadian } \\
\text { dollar }\end{array}$ & $\begin{array}{c}\text { British } \\
\text { pound }\end{array}$ & $\begin{array}{c}\text { Italian } \\
\text { lira } \\
\end{array}$ \\
\hline 1. & $\begin{array}{l}98.734 \\
(<.001)\end{array}$ & $\begin{array}{l}86.976 \\
(<.001)\end{array}$ & $\begin{array}{l}89.344 \\
(<.001)\end{array}$ & $\begin{array}{c}112.656 \\
(<.001)\end{array}$ & $\begin{array}{l}90.414 \\
(<.001)\end{array}$ & N.A. & N.A. \\
\hline 2 . & $\begin{array}{l}19.788 \\
(<.001)\end{array}$ & $\begin{array}{r}11.768 \\
(.001)\end{array}$ & $\begin{array}{l}5.518 \\
(.019)\end{array}$ & $\begin{array}{l}8.830 \\
(.003)\end{array}$ & $\begin{array}{l}0.000 \\
(.999)\end{array}$ & N.A. & N.A. \\
\hline 3. & $\begin{array}{l}69.282 \\
(<.001)\end{array}$ & $\begin{array}{l}63.468 \\
(<.001)\end{array}$ & $\begin{array}{l}67.052 \\
(<.001)\end{array}$ & $\begin{array}{l}92.226 \\
(<.001)\end{array}$ & $\begin{array}{l}56.516 \\
(<.001)\end{array}$ & $\begin{array}{l}34.092 \\
(<.001)\end{array}$ & $\begin{array}{r}230.242 \\
(<.001)\end{array}$ \\
\hline 4. & $\begin{array}{r}18.832 \\
(.001)\end{array}$ & $\begin{array}{l}7.952 \\
(.047)\end{array}$ & $\begin{array}{r}19.222 \\
(.001)\end{array}$ & $\begin{array}{r}13.580 \\
(.009)\end{array}$ & N.A. & $\begin{array}{r}16.862 \\
(.001)\end{array}$ & N.A. \\
\hline 5. & $\begin{array}{l}18.808 \\
(<.001)\end{array}$ & $\begin{array}{l}7.946 \\
(.019)\end{array}$ & $\begin{array}{c}17.402 \\
(.001)\end{array}$ & $\begin{array}{r}13.064 \\
(.005)\end{array}$ & N.A. & $\begin{array}{r}10.912 \\
(.004)\end{array}$ & N.A. \\
\hline 6. & $\begin{array}{c}12.222 \\
(.002)\end{array}$ & $\begin{array}{l}3.138 \\
(.076)\end{array}$ & $\begin{array}{l}17.060 \\
(<.001)\end{array}$ & $\begin{array}{r}11.536 \\
(.003)\end{array}$ & N.A. & N.A. & N.A. \\
\hline 7. & $\begin{array}{l}2.808 \\
(.246) \\
\end{array}$ & $\begin{array}{l}3.700 \\
(.157)\end{array}$ & $\begin{array}{l}3.942 \\
(.139) \\
\end{array}$ & $\begin{array}{l}2.176 \\
(.337) \\
\end{array}$ & $\begin{array}{l}18.784 \\
(<.001)\end{array}$ & $\begin{array}{r}10.862 \\
(.004) \\
\end{array}$ & $\begin{array}{l}3.738 \\
(.154) \\
\end{array}$ \\
\hline
\end{tabular}

Notes: The null hypotheses are the following: $1 .(\alpha=\beta=\delta=0) ; 2 .(\delta=0)$

3. $(\alpha=\beta=0) ; 4 \cdot\left(b_{0}=b_{1}=\rho_{1}=\rho_{2}=0\right) ; 5 .\left(b_{1}=\rho_{1}=\rho_{2}=0\right)$;

6. $\left(\rho_{1}=\rho_{2}=0\right) ; 7 .\left(b_{0}=b_{1}=0\right)$ 
TABLE 4

OLS TESTS OF THE MODEL

\begin{tabular}{|c|c|c|c|c|}
\hline \multicolumn{5}{|c|}{$\begin{aligned} \Delta \mathbf{s}_{\mathrm{t}}= & \beta_{0}+\beta_{1} \Delta \mathrm{h}_{1 \mathrm{t}}+\beta_{2} \Delta \mathrm{h}_{2 t}+\beta_{3} \Delta \mathrm{h}_{3 t}+\beta_{4} \Delta \mathrm{h}_{4 \mathrm{t}}+\beta_{5} \Delta \mathrm{m}_{1 \mathrm{t}} \\
& +\beta_{6} \Delta \mathrm{m}_{2 t}+\beta_{7} \Delta \mathrm{y}_{1 \mathrm{t}}+\beta_{8} \Delta \mathrm{y}_{2 t}+\beta_{9} \Delta \omega_{1 \mathrm{t}}+\beta_{10} \Delta \omega_{2 t}+\varepsilon_{t}\end{aligned}$} \\
\hline Variable & Coefficient & $\begin{array}{l}\text { Deutsche } \\
\text { mark }\end{array}$ & $\begin{array}{c}\text { Japanese } \\
\text { yen }\end{array}$ & $\begin{array}{c}\text { British } \\
\text { pound }\end{array}$ \\
\hline Constant & $\beta_{0}$ & $\begin{array}{c}0.003 \\
(0.003) \\
.295 \\
\end{array}$ & $\begin{array}{c}0.003 \\
(0.003) \\
.311 \\
\end{array}$ & $\begin{array}{c}-0.002 \\
(0.002) \\
.367 \\
\end{array}$ \\
\hline$\Delta \mathrm{h}_{\mathrm{y}}$ & $\beta_{1}$ & $\begin{array}{c}-79.881 \\
(66.951) \\
.235\end{array}$ & $\begin{array}{c}-10.347 \\
(60.989) \\
.866\end{array}$ & $\begin{array}{c}-6.430 \\
(56.422) \\
.320 \\
\end{array}$ \\
\hline$\Delta h_{y *}$ & $\beta_{2}$ & $\begin{array}{c}6.188 \\
(9.564) \\
.519\end{array}$ & $\begin{array}{c}21.728 \\
(50.771) \\
.669\end{array}$ & $\begin{array}{c}-0.082 \\
(3.788) \\
.983\end{array}$ \\
\hline$\Delta \mathrm{h}_{\mathrm{m}}$ & $\beta_{3}$ & $\begin{array}{c}238.440 \\
(167.465) \\
.157 \\
\end{array}$ & $\begin{array}{c}1.026 \\
(160.353) \\
.995 \\
\end{array}$ & $\begin{array}{c}-23.303 \\
(147.799) \\
.873 \\
\end{array}$ \\
\hline$\Delta \mathrm{h}_{\mathrm{m} *}$ & $\beta_{4}$ & $\begin{array}{c}-6.879 \\
(31.610) \\
.828 \\
\end{array}$ & & \\
\hline$\Delta \mathrm{m}$ & $\beta_{5}$ & $\begin{array}{c}0.585 \\
(0.630) \\
.355 \\
\end{array}$ & $\begin{array}{c}0.293 \\
(0.588) \\
.619 \\
\end{array}$ & $\begin{array}{c}1.021 \\
(0.561) \\
.071 \\
\end{array}$ \\
\hline$\Delta \mathrm{m}^{*}$ & $\beta_{6}$ & $\begin{array}{c}-0.464 \\
(0.409) \\
.258\end{array}$ & $\begin{array}{c}-0.172 \\
(0.229) \\
.453\end{array}$ & $\begin{array}{c}-0.448 \\
(0.251) \\
.076\end{array}$ \\
\hline$\Delta \mathrm{y}$ & $\beta_{7}$ & $\begin{array}{c}-0.414 \\
(0.291) \\
.157 \\
\end{array}$ & $\begin{array}{c}0.149 \\
(0.282) \\
.597 \\
\end{array}$ & $\begin{array}{c}-0.626 \\
(0.261) \\
.012 \\
\end{array}$ \\
\hline$\Delta y^{*}$ & $\beta_{8}$ & $\begin{array}{c}0.016 \\
(0.147) \\
.913 \\
\end{array}$ & $\begin{array}{c}-0.238 \\
(0.226) \\
.294 \\
\end{array}$ & $\begin{array}{c}0.234 \\
(0.156) \\
.136 \\
\end{array}$ \\
\hline$\Delta \omega$ & $\beta_{9}$ & $\begin{array}{c}-0.592 \\
(0.499) \\
.238 \\
\end{array}$ & $\begin{array}{c}-0.267 \\
(0.462) \\
.565 \\
\end{array}$ & $\begin{array}{c}-0.517 \\
(0.439) \\
.241 \\
\end{array}$ \\
\hline$\Delta \omega *$ & $\beta_{10}$ & $\begin{array}{c}0.065 \\
(0.267) \\
.807 \\
\end{array}$ & $\begin{array}{c}-0.009 \\
(0.140) \\
.946 \\
\end{array}$ & $\begin{array}{c}0.131 \\
(0.162) \\
.419 \\
\end{array}$ \\
\hline
\end{tabular}

Notes: The dependent variable is the rate of depreciation of the dollar relative to the foreign currency. Variables without an asterisk are U.S. values, and variables with an asterisk are foreign variables. The 
conditional variances are denoted with an $h$. F-statistics (with marginal levels of significance in parenthesis) and the adjusted $R^{2}$ 's for the equations are the following: Deutsche mark, $\mathrm{H}_{0}$ : all $\beta_{i}=0$, 0.735 (.691), $\mathrm{H}_{0}: \beta_{1}=\beta_{2}=\beta_{3}=\beta_{4}=0,0.820(.514), \mathrm{R}^{2}=-.017$; Japanese yen, $\mathrm{H}_{0}:$ all $\beta_{\mathrm{i}}=0,0.735$ (.691), $\mathrm{H}_{0}: \beta_{1}=\beta_{2}=\beta_{3}=0,0.080$ (.966), $\mathrm{R}^{2}=-.042 ;$ British pound, $\mathrm{H}_{0}:$ all $\beta_{\mathrm{i}}=0,1.296(.243), \mathrm{H}_{0}: \beta_{1}$ $=\beta_{2}=\beta_{3}=0,0.017(.993), \mathrm{R}^{2}=.016$. 